\title{
In or out? Poverty dynamics among older individuals in the $U K$
}

\author{
RICKY KANABAR \\ Institute for Social and Economic Research, University of Essex, Colchester CO4 3SQ, United Kingdom of \\ Great Britain and Northern Ireland \\ (e-mail: rkanabardessex.ac.uk)
}

\begin{abstract}
Using the largest household panel survey Understanding Society, this paper investigates lowincome dynamics among pensioner households in the UK controlling for biases due to initial conditions and non-random survey attrition. Estimation results indicate there is a correlation between initial and conditional poverty status, specifically, there is regression towards the mean. The results find no evidence of a correlation between initial poverty status, conditional poverty status and survey attrition. The findings show the importance of benefit income in determining poverty status, suggesting that a dichotomous measure such as poverty status may not suitably reflect actual pensioner living standards. Aside from benefit income, receipt of employer and occupational pension, health, education and subjective financial situation are important in determining initial and conditional poverty status. Stylised examples highlight the significant differences in the 'poverty experience' which arise due to differences individual and household characteristics.
\end{abstract}

JEL CODES: D31, J26

Keywords: Old age poverty, retirement, Understanding Society.

\section{Introduction}

In the UK a significant proportion of the population ( 1 in 6) is aged 65 and over, in addition both birth and cohort life expectancy is increasing (ONS, 2014, 2015). ${ }^{1}$ These issues are not unique to the UK, but shared by many developed economies and have led to the number of older individuals (globally) to rise significantly over the past 50 years (OECD, 2011). The OECD estimate that the average British female (male) at state pension age in 2010 should expect to live for an additional 24.5 (16.9) years, up from 22.7 (15.4) in 1999 (OECD, 2011). Abstracting from important issues such as health, a report by the Department for Work and Pensions in the United

1 Population estimates are based on 2011 Census data. See: http://www.ons.gov.uk/ons/rel/pop-estimate/ population-estimates-for-uk-england-and-wales-scotland-and-northern-ireland/mid-2014/index.html 
Kingdom estimated 1.8 million pensioners are living in poverty after accounting for housing costs (DWP, 2014). Therefore understanding pensioner poverty and pensioner living standards within the context of an ageing population in the UK is an important policy issue; moreover, it also has implications for advanced economies with a similar welfare system.

The welfare system in the UK provides pensioners on low income with particular benefits, the main supplementation programme being Pension Credit. ${ }^{2}$ Expenditure on Pension Credit is significant, in the tax year 2013-2014 £6.233 billion pounds was spent on Guarantee Credit which is a specific subcomponent of Pension Credit available to pensioners on particularly low incomes (DWP, 2015). ${ }^{3}$ Alongside Pension Credit social benefit income plays an important role in determining a pensioner's income position. Specifically, pensioners are a group of individuals for whom health-related benefits such as incapacity, disability, carers/attendance allowance and housing benefit account for a significant proportion of their income. Aside from the significant fiscal implications of such benefits; this also implies that when analysing a pensioner's standard of living using income-based measures it is important to pay particular attention to their health and the types of benefit income they are entitled to and report being in receipt of.

The fiscal implications of an ageing society highlight the need to understand lowincome dynamics among the pensioner population. Specifically, how important are particular factors in determining whether a pensioner enters, transitions out of or persists in poverty? Indeed, how much does income change in retirement? Given the potential sources of income available one might expect an individual's income to remain relatively constant in retirement. Research which analyses low-income dynamics also has implications for policy; for example to quantify the importance occupational pensions on poverty dynamics. However, does a transition out of poverty necessarily mean an individual's standard of living has improved? A pensioners standard of living (in terms of both income and health) is a function of factors accumulated over the lifecourse such as work history and health behaviours, and also exogenous shocks such as disability or the onset of an age-related disease.

Using the largest country-specific household panel survey Understanding Society this paper provides the first estimates of low-income dynamics among British pensioner households, which also account for biases which may arise due to initial conditions and non-random attrition. I investigate the sources which determine poverty status and consider whether poverty transitions actually correspond to a change in an individual's standard of living. The first-order Markov framework followed in this paper allows me to explore how differences in individual and household-level characteristics affect the likelihood of entering poverty, poverty persistence and duration in and between poverty spells.

The results imply a high degree of aggregate state dependence for this group of individuals. The estimation results also suggest that the likelihood of entering poverty, poverty persistence and duration in and between poverty spells varies significantly

${ }^{2}$ Pension Credit is available to individuals aged 65 and over. It is made up of two components: Guarantee Credit and Savings Credit. Guarantee Credit is eligible to pensioners on low income and Savings Credit is eligible to pensioners who made some private saving towards retirement.

3 Based on DWP estimates. See https://www.gov.uk/government/statistics/benefit-expenditure-and-caseloadtables-2015 
depending on individual and household-level characteristics. Specifically, housing tenure, the presence of an occupational/employer pension and disability benefits are particularly important in determining these quantities of interest. From a methodological viewpoint the results suggest strong evidence of an initial conditions problem when analysing poverty transitions among this group. Specifically, there is a large degree of mean reversion which is driven by individual investment, pension and social benefit income. The fact that social benefit income, in particular disability income, plays an important role in determining poverty transitions highlights the fact that unlike in conventional studies of poverty dynamics of the working age population, a simple dichotomous measure such as being poor or non-poor may not necessarily truly reflect a pensioners actual standard of living. ${ }^{4}$

The rest of this paper is set out as follows. Section 2 briefly reviews the literature on pensioner income dynamics and modelling individual-level transitions. Section 3 describes Understanding Society, variable definitions and instruments used for model identification. Section 4 presents the main results and various sensitivity analyses to check the robustness of my results. Section 5 considers model implications. Section 6 concludes.

\section{Pensioner poverty and modelling transitions}

\subsection{Pensioner poverty}

Bardasi et al. (2002) using longitudinal data from the 1990s investigate how the onset of retirement is correlated with becoming poor. Their findings show that retired individuals are more likely to be poorer than the rest of the population but that over their sample period (1991-1997) the incomes of this group actually rose. The authors also found that retirement was associated with decline in an individual's economic wellbeing. Their analysis highlighted the importance of the period prior to retirement, in the case of men they found being in full-time employment significantly reduced the likelihood of becoming poor. However, for women labour market history was not important, but instead living in social housing, not being a member of an occupational pension scheme and retiring before the state pension age all raised the likelihood of becoming poor (Bardasi et al., 2002).

Similarly Jenkins and Rigg (2001) investigate the dynamics of poverty in Britain using longitudinal data from the 1990s. The authors jointly model flows into and out of poverty and also account for unobserved heterogeneity. Their findings showed that households with a pensioner were: (1) more likely to be persistently in poverty relative to other types of households; (2) more likely to enter or exit poverty due to changes in non-benefit non-labour income (i.e., pensions); (3) more likely to enter or exit poverty due to changes in health (the importance of benefit income); and (4) relative to other household types more likely to experience longer poverty spells. The authors conclude that income supplementation programmes such as Minimum

4 Moreover, the lack of data relating to disability care costs means it is not possible to calculate an adjusted income measure which would give a better estimate of an individual's standard of living. For more information see Hancock et al. (2015). 
Income Guarantee (the predecessor to Pension Credit) are required to keep these households out of poverty. The DWP have also analysed low-income dynamics at older ages as part of their annual Households Below Average Income (HBAI) publication. ${ }^{5}$ Their findings generally mirror those found by Jenkins et al. (2001), in addition, given the long series of the HBAI publication the general trend from the analysis has pointed towards a decline in poverty persistence among pensioners; however, in their most recent publication the DWP have noted pensioner poverty has started to rise again (DWP, 2015). ${ }^{6}$ The report also highlighted the relatively high rate of persistent poverty among single pensioner households and that pensioner households had relatively low exit rates from poverty compared with other groups.

Brewer et al. (2007) investigate the implications of the 2006 White Paper on pensioner poverty. Their main finding indicates that pensioner poverty is likely to remain relatively stable between $2007 / 8$ and $2017 / 18$, principally due to the fact that the UK government committed to indexing pension credit in line with earnings. However, their findings also highlight that relatively low-income pensioner households stand to lose out due to cuts to the generosity of the Savings Credit component of Pension Credit. Clark (2001) and Brewer and Emmerson (2003) both investigate the implications of Pension Credit, a benefit available to individuals when they are eligible to claim their state pension. The research shows that whilst Pension Credit helps boost income for the poorest pensioners there are also income and substitution effects which may affect saving for retirement. In addition, the authors highlight eligible individuals face a relatively high marginal withdrawal rate especially after accounting for other types of benefits these individuals are entitled to.

The majority of these papers use household surveys to investigate particular aspects of poverty dynamics at older ages, two potentially important factors have been largely unaccounted for. The first is related to data; the majority of studies which have analysed pensioner poverty dynamics have used a hazard regression framework. Such models cannot accommodate left censored data, this raises issues concerning how representative the estimation sample is for the purposes of analysis and also drawing policy implications from such studies. Second, existing studies have not paid particular attention to survey attrition. ${ }^{7}$ Specifically, whether there exists correlated unobserved factors effecting survey retention and/or low income; accounting for this will eliminate biases which arise due to non-random attrition. For pensioners, attrition may occur due to health shocks, a general decline in health due to age or the accumulation of poor health over the lifecycle; previous studies have emphasised the importance of controlling for non-random attrition when modelling particular types of transitions using representative household panel surveys (see inter-alia Jenkins and Rigg, 2001; Jones et al., 2006; Cuervo and Pudney, 2013). The framework described in Section 3.3 formally accounts for such biases.

\footnotetext{
5 As of 2010 this publication is no longer produced; the latest version covers the period 2001-2008.

${ }^{6}$ Findings are reported based on sample data without accounting for housing costs.

7 A potentially more serious issue is initial non-response (see inter alia Bethlehem et al., 2011; Little and Rubin, 2014), however fitting a model which accounts for initial conditions, non-random survey attrition and initial non-response is likely to be very complicated.
} 


\subsection{Modelling individual-level transitions}

Jenkins (2011) provides an excellent review of the standard approaches used to model income dynamics using individual-level microdata. The majority of these approaches fall into one of six categories: (1) dynamic binary choice (random effects) models, (2) hazard models, (3) structural models, (4) variance component models, (5) multi-state models and (6) endogenous switching models. ${ }^{8}$ I briefly discuss the strengths and weaknesses of each type of approach and emphasise the reasons why I choose to model low-income dynamics using an endogenous switching framework.

Arulampalam and Stewart (2009) suggest that the main reason economists use dynamic binary choice (random effects) models is to capture state dependence. These models have the advantage of controlling for initial conditions (Heckman, 1981) and individual-specific unobserved heterogeneity, factors which the basic transition model developed by Boskin and Nold (1975) fails to incorporate (Wooldridge, 2005). ${ }^{9}$ However, Biewen (2009) highlights one notable drawback to dynamic binary choice models is that they do not allow for feedback effects, namely the framework assumes the dependent variable in period $t-1$ is uncorrelated with covariates in period $t$ (one recent exception is Ayllón, 2015). This particularly important in the context of modelling low-income dynamics, previous studies have found strong evidence of feedback effects (Cappellari and Jenkins, 2004; Arulampalam and Stewart, 2009; Biewen, 2009; Fusco and Islam, 2012).

Hazard or duration models have been widely used to model individual-level dynamics (Jenkins, 2011). Jenkins and Rigg (2001), Devicienti (2002) and Bardasi et al. (2002) use a duration framework to model low-income dynamics using the British Household Panel Survey. Such models pay particular attention to the amount of time an individual is in a particular state prior to a transition out of that state; therefore relative to other approaches individual dynamics are modelled in a sophisticated manner. However, hazard models often assume individual-level unobserved effects are independent of entry to the initial state and ignore sample attrition (Cappellari and Jenkins, 2004). ${ }^{10,11}$ Another drawback is that hazard models cannot accommodate left censored observations, this includes individuals who at each wave of the sample remain in the same state (in the context of this paper being 'poor' or 'non-poor'). This will bias estimates by dropping a large number of observations and hence make the sample unrepresentative, this bias is compounded by the fact that hazard models cannot accommodate survey weights which account for non-random attrition.

${ }^{8}$ I do not discuss counter-factual decomposition methods; however for an excellent summary, readers should consult Aassve et al. (2006).

9 Nonetheless Jenkins and Cappellari (2008) note the model presented in Boskin and Nold (1975) serves as a useful benchmark and has the advantage of having closed form expressions for estimating durations of interest assuming variables have reached their steady-state values.

10 A few notable exceptions include Jenkins and Rigg (2001) who jointly model poverty flows and account for unobserved heterogeneity; see also Stevens (2011) and Devicienti (2002).

11 Unobserved heterogeneity can be incorporated into hazard models (see, e.g., Lancaster, 1990 or Jarvis and Jenkins, 1997); however this requires making parametric or non-parametric assumptions to summarise the distribution of unobserved heterogeneity. Moreover, a further drawback to this approach is that survey weights which control for survey attrition cannot be applied to such models. 
Structural models pay particular attention to individual dynamics (for example, labour supply and earnings) whilst also recognising that these factors determine a households income position (see inter-alia Burgess and Propper, 1998; Aassve et al., 2006). Using a structural approach Biewen (2009) analyses poverty dynamics and the role of feedback effects using German longitudinal household panel data. His findings indicate the main channels by which the feedback mechanism effects current poverty is via an individual's employment status and their household composition. Whilst structural models are appealing from a theoretical perspective they are complex to estimate, require many waves of rich longitudinal survey data and also require a number of strict assumptions to hold. The strict assumptions relate to the way the individual fixed effects and general feedback effects operate; however this is unlikely to be a serious issue for pensioners. This is due to the fact that the main channels by which these feedback effects affect contemporaneous poverty (via changes in employment and changes in household composition due to marriage and separation) are likely to be occuring in low numbers or largely inapplicable to pensioner households. ${ }^{12}$ Another drawback of structural and dynamic random effects or fixed effects approaches is that these estimators require the use of a balanced panel and in many cases ignore sample attrition. ${ }^{13}$

Variance component models decompose the permanent and transitory components of an individual's income series, the majority of studies using this framework have applied it to longitudinal US or Canadian data (Jenkins, 2011). One exception is Blundell and Etheridge (2010) who apply this method to British longitudinal panel data. The authors show there has been a strong growth in the variance of permanent and transitory income shocks; and that there has been growth in permanent shocks to labour income, together these findings help explain the changes in income inequality witnessed in the UK between 1980 and 2000. Whilst variance component models are able to shed light on the components of the income process and how they change over time, critics have argued such models are sensitive to changes in model specification (Shin and Solon, 2011). These models also rely on observing income at each period and therefore do not control for non-random survey attrition which may bias results. ${ }^{14}$ Moreover, variance component models also assume the income process is homogeneous across all individuals, an assumption rejected by Stevens (2011). ${ }^{15}$

12 Biewen (2009) interest is in modeling poverty dynamics among working age men; therefore it is not surprising employment and household composition have feedback effects. However, in the case of pensioner households these factors are likely to play a less significant role; for example the rate of unretirement (defined as a transition from retirement back into paid employment) is relatively low in England (see Kanabar, 2015) and a change in household composition is most likely to be due to a pensioner losing their spouse, however in many cases the surviving spouse has access to some or all of their (no deceased) spouse's pension and therefore the extent to which a pensioner will experience a large unexpected change to their income is mitigated. Another example might be sudden changes in health; however these are also unlikely to affect household income given that free universal healthcare is available in the UK.

13 Although some authors have extended the basic framework and controlled for attrition using longitudinal weights, see Biewen (2009).

14 Some studies such as Biewen (2009) have extended the standard variance component framework to incorporate longitudinal survey weights.

15 Hazard, random effects and Markov models do not assume a homogeneous income process across all individuals but allow for this process to differ conditional on poverty status. 
Multi-state frameworks are another class of models which have been used to analyse changes in household circumstances. Aassve et al. (2006) emphasise the role of economic behaviour and how optimal decision-making over various dimensions such as employment, fertility and marital status determine an individual's overall economic position, and hence whether he is in poverty or not. These models are inherently complex and also do not allow for feedback effects. ${ }^{16}$ Moreover, the focus of this paper is to understand low-income dynamics among pensioner households therefore similar to the argument made against the use of a structural model, it is questionable whether any of the key decision-making processes highlighted above are likely to be of relevance or affect the economic position of pensioner households.

Endogenous switching models have been used to study poverty and low pay dynamics in the UK (Stewart and Swaffield, 1999; Cappellari and Jenkins, 2004, 2008). The endogenous switching model of Cappellari and Jenkins $(2004,2008)$ controls for the initial conditions problem, left censored data and also survey attrition. The framework allows for specific feedback effects by interacting the dependent variable at period $t-1$ with covariates (also measured at period $t-1$ ) in determining their impact on the outcome of interest in period $t$. This implies one can investigate the extent of state dependence whilst controlling for individual-level observed and unobserved heterogeneities. Another advantage of this framework is that it can be applied to relatively short panels (as a minimum it only requires two waves of data). However, it is worth noting that there are also drawbacks to this approach; for example, Biewen (2009) notes that the structure of the endogenous switching framework implies that poverty at $t-1$ captures all relevant information in determining poverty at period $t$. A recent paper by Bhuller et al. (2016) investigating welfare receipt using administrative Norwegian monthly panel data show that this 'conditional Markov property' fails to hold. Arranz and Canto (2008) also note the importance of retrospective data in determining contemporaneous poverty, specifically an individual's poverty history (time spent in and out of poverty). The extent to which this may cause a bias in estimates is mitigated by the fact that the approach used in this paper controls for unobserved heterogeneity, as pointed out in a recent paper by Fusco and Islam (2012). The fact that I use pairs of consecutive waves of data means I cannot fully exploit the time dimension of the panel and the modelling framework cannot determine the nature and direction of any potential feedback effects. ${ }^{17}$ Endogenous switching models use covariates at $t-1$ to predict poverty at period $t$ : this rules out accounting for any potential changes between these periods. This may be important for pensioners, for example being eligible to claim a pension or particular benefit. In order to address this issue Section 6 describes the components of income, which are attributable to the changes in income and poverty status between $t-1$ and $t$.

16 An exception here is Biewen (2009).

17 Bhuller et al. (2016) using Norwegian administrative using monthly micro-level data show that the conditional Markov property has implications for the aggregation of a dynamic processes over time. Their findings show the estimated state dependence is affected time aggregation bias if the conditional Markov assumption is violated, nonetheless they find even more complex higher-order structures are unable to satisfactorily account for the true data-generating process. 


\subsection{First-order Markov model}

The analytical framework used in this paper relies on the endogenous switching framework developed by Cappellari and Jenkins (2004). The following exposition draws heavily on their work.

The outcome of interest, poverty and the transitions to and from this state are modelled between two consecutive years, $t-1$ and $t$. Initial poverty status at $t-1$ is determined by the latent propensity $p_{i, t-1}^{*}$ :

$$
p_{i, t-1}^{*}=\beta^{\prime} x_{i, t-1}+\varepsilon_{i, t-1},
$$

where $i=1, \ldots, N$ indexes individuals, $x_{t-1}$ contains information relating to individual $i$ and the household they live in, $\beta$ is a vector of parameters to be estimated and $\varepsilon_{i, t-1} \sim N(0,1)$ is the sum of an individual-specific effect $\zeta_{i}$, and a white noise error $l_{i, t-1} \cdot{ }^{18} \mathrm{An}$ individual is poor if their latent poverty propensity exceeds 0 .

The second equation of interest relates to an individual's survey retention probability, formally this defined as whether I observe their household income in period $t$ conditional on having observed it at $t-1$. This is modelled by the latent propensity $r_{i, t}^{*}$ :

$$
r_{i, t}^{*}=\gamma w_{i, t-1}+\kappa_{i, t},
$$

where $i=1, \ldots, N$ indexes individuals, $w_{i, t-1}$ contains many of the same elements also in the vector $x_{i, t-1}$, but also some variables which are correlated with the likelihood of survey retention but uncorrelated with initial poverty and hence excluded from $x_{i, t-1}$ (these variables or so-called instruments are described in detail in Section 3), finally $\gamma$ is a vector of parameters to be estimated. ${ }^{19} \kappa_{i, t} \sim N(0,1)$ is the sum of an individualspecific effect $\omega_{i}$ and a white noise error $\varepsilon_{i, t}$. If an individual's latent propensity is $>$ 0 , then I observe their income in period $t$, otherwise I do not. If I do not observe household income in period $t$ then it is neither possible to determine an individual's period $t$ poverty status, nor any poverty transition which may have taken place.

The final equation describes poverty status in period $t$. This is characterised by the latent propensity $p_{i, t}^{*}$ :

$$
p_{i, t}^{*}=\left[\left(P_{i, t-1}\right) \theta_{1}^{\prime}+\left(1-P_{i, t-1}\right) \theta_{2}^{\prime}\right] s_{i, t-1}+\vartheta_{i, t},
$$

where $i=1, \ldots, K$ indexes individuals (where $K<N$ due to survey attrition), $s_{i, t-1}$ contains variables, which are similar to those contained in $x_{i, t-1}$ with the exception that they have been interacted with $P_{i, t-1} .{ }^{20}$ Similar to the retention equation the estimation strategy pursued in this paper requires that there must exist variables, which are correlated with determining initial poverty, but, conditional on this uncorrelated with poverty transition and so are excluded from equation 3 (these instruments are described in Section 4.3), finally $\theta_{1}, \theta_{2}$ are vectors of parameters to be estimated. $\vartheta_{i, t} \sim N(0,1)$ is the sum of an individual-specific effect $\tau_{i}$ and a white noise error $\varsigma_{i, t}$.

18 Any residual is subsumed into the error term and we formally test for correlation between initial poverty, income retention and poverty transition.

19 In an alternative specification of the model I included the instruments used to control for survey retention in the initial poverty equation and found they were not significant.

20 In order to avoid simultaneity between changes in attributes and changes in poverty status we control for characteristics at $t-1$ in equation (3). 
We assume an individual is in poverty in period $t$ if their latent propensity exceeds 0 , similar to equation 2 we can only observe $P_{i, t}$ if an individual does not attrite from the survey and we observe their household's income in period $t .^{21}$

We estimate the model free of any restrictions and assume the joint distribution of the error terms is trivariate standard normal. Unobserved heterogeneity can be summarised by the following three correlation coefficients:

$$
\begin{gathered}
\rho_{1} \equiv \operatorname{corr}\left(\varepsilon_{i, t-1}, \kappa_{i, t}\right)=\operatorname{cov}\left(\zeta_{i}, \omega_{i}\right), \\
\rho_{2} \equiv \operatorname{corr}\left(\varepsilon_{i, t-1}, \vartheta_{i, t}\right)=\operatorname{cov}\left(\zeta_{i}, \tau_{i}\right), \\
\rho_{3} \equiv \operatorname{corr}\left(\kappa_{i, t}, \vartheta_{i, t}\right)=\operatorname{cov}\left(\omega_{i}, \tau_{i}\right) .
\end{gathered}
$$

The cross-equation correlations summarise the unobserved heterogeneity affecting initial poverty, income retention and poverty transition. As Cappellari and Jenkins (2004) note the association between unobservable factors, which determine initial poverty and whether a respondent reports their income in a subsequent wave is captured by $\rho_{1}$. If $\rho_{1}>0$ (resp. $<0$ ), this indicates that those individuals who are more likely to initially be in poverty at $t-1$ are more (resp. less) likely to report their income/ belong to a household which reports their income in the subsequent wave relative to an individual who is non-poor in $t-1$. The correlation $\rho_{2}$ captures unobserved factors which determine initial poverty status and poverty transitions (i.e., conditional poverty). If $\rho_{2}>0$ (resp. $\left.<0\right)$ this implies individuals who have a higher probability of initially being in poverty in $t-1$ are more (resp. less) likely to be in poverty in the subsequent period relative to individuals who were initially non-poor in $t-1$. The correlation $\rho_{3}$ captures unobserved factors which determine income retention and conditional poverty status. If $\rho_{3}>0$ (resp. $<0$ ), this implies the likelihood of remaining in poverty is higher (resp. lower) for individuals for whom we observe household income in $t-1$ and $t$, relative to individuals who are more likely to attrit from the survey between period $t-1$ and $t$. The model structure imposed by the framework implies it is possible to formally test for whether initial conditions $\left(\rho=\rho_{2}=0\right)$ and/or income retention $\left(\rho_{1}=\rho_{3}=0\right)$ are exogenous, these results are reported in Section 5.5.

\subsubsection{Poverty transition probabilities}

The estimation strategy followed in this paper implies it is possible to analyse three measures of poverty dynamics: (1) Poverty persistence $\left(m_{i, t}\right)$; (2) Poverty entry $\left(l_{i, t}\right)$; (3) Poverty exit $\left(e_{i, t}\right)$. Cappellari and Jenkins (2004) show that in the context of a first-order endogenous switching model these three statistics are defined as:

$$
m_{i, t} \equiv \operatorname{Pr}\left(P_{i, t}=1 \mid P_{i, t-1}=1\right)=\frac{\Phi_{2}\left(\theta_{1}^{\prime} s_{i, t-1}, \beta^{\prime} x_{i, t-1} ; \rho_{2}\right)}{\Phi\left(\beta^{\prime} x_{i, t-1}\right)},
$$

21 Jenkins et al. (2006) estimate a first-order Markov system with four equations for analysing low-income dynamics, the extra equation (which we exclude for the purposes of our analysis) is an employment equation. This latter equation is not applicable for our study given that we condition on individuals in selfreported retirement, only a tiny proportion $(<1 \%)$ unretire by the following wave, nonetheless unretirement may be more prevalent over a long-time horizon (Kanabar, 2015). In addition, such an estimation strategy would require exclusion restrictions, which would imply there existed covariates, which were correlated with employment, but uncorrelated with initial poverty status, reporting income and poverty status in the next period. 


$$
\begin{gathered}
l_{i, t} \equiv \operatorname{Pr}\left(P_{i, t}=1 \mid P_{i, t-1}=0\right)=\frac{\Phi_{2}\left(\theta_{2}^{\prime} s_{i, t-1},-\beta^{\prime} x_{i, t-1} ;-\rho_{2}\right)}{\Phi\left(-\beta^{\prime} x_{i, t-1}\right)}, \\
e_{i, t} \equiv \operatorname{Pr}\left(P_{i, t}=0 \mid P_{i, t-1}=1\right)=1-(7),
\end{gathered}
$$

where $\Phi_{2}$ and $\Phi_{1}$ are the bivariate and univariate cumulative density function of the standard normal distribution. By explicitly accounting for the retention propensity in (2) it is possible to estimate transition rates robust to non-random attrition for respondents who were present in period $t-1$ but for whatever reason had dropped out at the survey by $t$.

Poverty durations: A central measure of interest when analysing poverty dynamics is the duration an individual spends in or out of poverty. One particular feature of the first-order Markov framework followed in this paper is that it is possible to estimate such poverty durations, for example the (mean and median) time an individual is expected to spend in a particular state and the (mean and median) time period between states (Boskin and Nold, 1975; Cappellari and Jenkins, 2004). In Section 5.2, I present estimates of these quantities of interest using stylised individuals. ${ }^{22}$

\section{Data and definitions}

\subsection{Understanding society}

The sample used in this study is drawn from Understanding Society (UKHLS), a nationally representative large-scale annual household panel survey which (as a subsample) includes its predecessor the British Household Panel Survey (BHPS). Understanding Society is an initiative which is managed by the Institute for Social and Economic Research based at the University of Essex; for more information see Knies (2014).

This study pools waves $2-4$ of the survey which corresponds to the calendar period 2010-2013.23 I restrict the sample to individuals who (at wave 2) are aged at least 60 if they are female and 65 if they are male and report being in retirement and live in a household which is defined as a 'single' or 'couple' pensioner household. After imposing these sample restrictions and cleaning the data there are 12,904 individuals at $t-1$ eligible to be in the sample, of which 1,796 (14\%) attrit by $t$. Table 1 highlights the pattern between poverty status and survey attrition and also shows the extent of left censored data in the sample, i.e. individual's whose poverty status in both $t$ and $t+1$ is identical.

Two notable findings emerge from Table 1. First, a large proportion of individuals remain in the same state across two survey waves, for example $58 \%$ of individuals remain in poverty, whilst nearly $78 \%$ are not in poverty in both $t-1$ and $t$. This underlines the advantage of using the first-order Markov approach when only having a few waves of survey data: $73 \%$ of observations would be dropped if one instead

22 Appendix A states the expressions used to derive the quantities of interest. The estimated durations are based on the point estimates presented in Tables 4-6.

23 Income data from wave 1 of UKHLS underestimates income from particular types of benefit sources; however the design of the survey means from wave 2 onwards survey techniques such as dependent interviewing and panel conditioning mean a more accurate measure of individual (and therefore household) income is recorded. For more information see Fisher (2015). 
Table 1. Poverty status and attrition

\begin{tabular}{llccc}
\hline \hline & \multicolumn{3}{c}{$\mathrm{T}$} \\
\cline { 2 - 4 }$t-1$ & \multicolumn{1}{c}{ Non-poor } & Poor & Missing & \multirow{2}{*}{ Total } \\
\hline Non-poor & $77.99 \%(7,377)$ & $8.18 \%(774)$ & $13.83 \%(1,308)$ & $100 \%(9,459)$ \\
Poor & $27.08 \%(939)$ & $58.75 \%(2,024)$ & $14.17 \%(482)$ & $100 \%(3,445)$ \\
Total & $64.40 \%(8,310)$ & $21.68 \%(2,798)$ & $13.92 \%(1,796)$ & $100 \%(12,904)$ \\
\hline \hline
\end{tabular}

Notes: Sample is based on UKHLS waves 2-4. Author's calculations, for more information see text.

opted to use a hazard approach, which cannot accommodate left censored data. Second, the difference in the attrition rate between individuals who are initially non-poor versus those who are poor appears to be small. The main reason individual's attrited from the sample is due to outright refusal (4\%) and death (1.4\%).

A key concept in this paper is the definition of poverty. I use an income-based measure. This is based on information reported by survey respondents at the time of the interview and is composed of all sources of labour income, miscellaneous income, private benefit income, investment income, pension income and social benefit income. Each wave of Understanding Society data contains a derived household net income variable, this variable sums all individual incomes within the household having taken account of any taxes and (claimed) benefits individuals are liable for or entitled to. ${ }^{24}$ From this figure housing costs which may consist of rent, water rates, community water charges and council water charges, mortgage interest payments, ground rent and service charges and council tax are deducted. ${ }^{25}$ The British DWP the government department responsible for state pensions and reducing pensioner poverty refer to this as poverty After Housing Costs (AHC) and it is their preferred measure when analysing low-income dynamics among pensioner households. The reason for this is that: (1) a high proportion of pensioners own their own home outright; (2) in deriving poverty thresholds one should account for differences in housing costs relative to working-age households; (3) to account for interest rates; and (4) to account for increases in rent (DWP, 2015).

Having created a measure of poverty AHC, I follow the DWP and Office for National Statistics (ONS) and define an individual as being in poverty if he/she belongs to a household whose income is below $60 \%$ of real median equivalised net household income. ${ }^{26,27}$ The real monthly net equivalised income which defines the

24 For more information regarding the derivation of the net income variable see Knies (2014).

25 Understanding Society asks respondents for a composite measure of rent and flags whether this includes water rates. For respondents whose rent does not include water rates it is not possible to deduct this from their net income; however water rates are likely to constitute only a small proportion of total housing costs.

${ }^{26}$ I adjust household size using the OECD equivalence scale. For the purpose of estimating the poverty line at each wave the entire Understanding Society sample is used (the data are weighted to account for survey design and to ensure it is representative of the UK population).

27 As a robustness check I re-estimated the model using a poverty threshold based on the real net income Before Housing Costs; the headline findings are very similar to those reported AHC. 
AHC poverty threshold for 2010,2011 and 2012 was $£ 650, £ 667.78$ and $£ 662.13$, respectively (2005 prices).

\subsection{Variables}

Understanding Society contains a wide range of economic and sociodemographic variables, which are available at every wave of the survey. ${ }^{28}$ In keeping with previous studies of poverty the majority of covariates are defined at the level of Head of Household $(\mathrm{HoH})$. The $\mathrm{HoH}$ is defined as the individual within the household who contributes the greatest share of household income. Understanding Society provides the fraction of household income attributable to each person living in the household. ${ }^{29}$

Health has been shown to be an important characteristic determining the standard of living in older age (Banks and smith 2006; Jones et al., 2010). I control for selfreported health which is recorded on a five-point scale and whether an individual has a health limitation or disability, I also interact these two controls to determine their joint effect. Understanding Society asks sample respondents whether they have caring responsibilities for another household member, this is likely to affect an individual's ability to work or constrain the number of hours they can work. Part of the cost may be offset if the individual is entitled to attendance or carer's allowance to help with care. I separately control for whether an individual is in receipt of particular disability benefits including: incapacity/severe disablement (including industrial injury/sickness accident) and carer's or attendance allowance.

Bozio et al. (2011) using administrative linked data show educational attainment and pension type are important in determining an individual's economic position in retirement. I include a control for highest level of educational attainment (five-point scale) and the type and number of pensions an individual is in receipt of. ${ }^{30}$ Related to pension receipt, Stewart (2003) using the BHPS highlights the importance of an individual's earnings history in determining their income and wealth position in retirement. At the time of writing retrospective employment history data for Understanding Society sample respondents is unavailable; however, I control for the type and number of pensions an individual is receiving income from and this is likely to be strongly correlated with their labour market history. Understanding Society also asks sample respondents to report their income sources; I control for whether an individual is in receipt of investment income, private benefit income and miscellaneous income.

${ }^{28}$ One limitation of Understanding Society is that it does not contain data on pension wealth; although for the majority of the sample this is likely to have been annuitised and become part of individual (and thus household) income.

${ }^{29}$ In cases where the contribution to household income in a two person pensioner household is identical then whoever is oldest is defined as the $\mathrm{HOH}$; if this is also identical then in these very few cases the male is assumed $\mathrm{HoH}$.

${ }^{30}$ Bozio et al. (2011) use National Insurance contribution histories linked to the English Longitudinal Study of Ageing to investigate the heterogeneity in pension wealth holdings. Whilst Understanding Society does not contain data on pension wealth the fact this study is based on individuals in retirement who are at or above state pension age implies that such individuals will already be drawing down on their pension wealth and using it as a source of income (which is used to define whether they are in poverty) 
Marital status is another characteristic which has been shown to influence household income in retirement. Jenkins and Rigg (2001) using the BHPS found that over a four-wave window $55 \%$ of single pensioner households experienced poverty at least once, whilst the equivalent figure for pensioner couples was lower at $38 \%$. Jarvis and Jenkins (1997) also using the BHPS find 1/3 of male and 1/2 of female single pensioner households are likely to experience persistent poverty.

Similarly, housing tenure has been shown to be an important determinant of an individual's standard of living in retirement (Bardasi et al., 2002; Disney et al., 2002). Specifically, housing costs effect an individual's financial resources available for consumption, ceteris paribus a homeowner will have a higher level of disposable income (after accounting for housing costs) relative to an individual who has a mortgage or rents (Campbell and Cocco, 2007). Homeowners also have a higher stock of wealth and are able to release equity through downsizing or taking an additional mortgage, therefore this group of individuals is likely to be less credit constrained relative to households who still have an outstanding mortgage, are in social housing or renting. However, it is important to note that poor non-homeowner pensioners may be in receipt of particular benefits which boost their individual/household income.

I also control for an individual's subjective financial situation at the time of the survey interview, which is likely to be related to their poverty status. Stewart (2009) uses such a measure to derive a pensioner equivalence scale using longitudinal British panel data, his findings suggest that the current equivalence scale used by the state is more generous than that implied using his constructed scale using subjective financial expectations data. Finally, Brewer et al. (2007) show there exists significant variation over time in household income by Government Office Regions in the UK. Therefore I control for the government office region in which a household resided in.

\subsection{Model identification}

In order to model dynamics one must first observe an individual's initial income position; however, this is unlikely to be random. Indeed many studies have highlighted the significant differences in individual's financial position on reaching retirement (see inter-alia Diamond and Hausman, 1984; Kapteyn et al., 2005; Lusardi and Mitchell, 2007). Bozio et al. (2011) highlight the importance of state and private pension contributions (from lifetime earnings) in determining retirement income. Their results suggest that differences in retirement income are largely due to marital status and individual's numerical proficiency. Therefore it is important to account for individual heterogeneity when modelling low-income dynamics, this is often referred to as the initial conditions problem (Heckman, 1981). Ignoring the initial conditions problem in the context of low-income dynamics using survey data will lead to a bias in model estimates and implied durations of interest (Jenkins, 2011).

For the purposes of model identification and to eliminate such biases, I must assume particular exclusion restrictions. Cappellari and Jenkins (2004) highlight that for the modelling strategy to be successful one needs an instrument which is correlated with initial poverty at $t-1$ but conditional on this is uncorrelated with poverty status 
at $t$. Heckman (1981) suggests that one should use information prior to an individual's own labour market entry. Therefore I utilise data on respondent's paternal level of educational attainment. One could also use information collected about maternal level of educational attainment; however, this did not satisfy the conditions for being a satisfactory instrument. This covariate had low power in determining initial poverty equation at $t-1$, this is related to the fact that there is little variation in the level of maternal educational attainment for the sample of individuals used in this paper. Paternal educational attainment is coded as a dummy variable which takes the value 1 if a sample respondent's father left full-time education with a qualification or a degree and 0 otherwise. A priori (and holding all else constant) one would expect individuals who grew in up in a household with a more highly educated father to be less likely to experience poverty during their lifetime including when in retirement; indeed a large body of evidence has shown there exists positive intergenerational earnings mobility and a positive correlation between parent's and children's earnings (see inter-alia Behrman and Taubman, 1990; Grawe, 2006; Nicoletti and Ermisch, 2008). Table 3 in Section 3.4.1 shows that $16 \%$ of non-poor households had a $\mathrm{HoH}$ whose father left education with a recognised qualification or degree, whilst this figure stood at only $13 \%$ in poor households. In Section 5.5.1, I describe various tests to ensure the validity of paternal educational as an instrument to deal with the initial conditions problem.

A second instrument is required to control for non-random attrition. The instrument should be correlated with sample retention status but conditional on this be uncorrelated with poverty status at $t$. Understanding Society contains data collected by the fieldwork interviewer, which characterises certain aspects of the survey interview. ${ }^{31}$ Specifically, Understanding Society collects data on whether during the survey interview a survey respondent mentions:

1. Purpose of the survey (e.g., what's the purpose? what's all this about?)

2. Interview length (e.g., how long will this take?)

3. Panel design (e.g., you'll be coming back next year?)

4. Confidentiality (e.g., who is going to see the answers?)

5. Incentive/payment (e.g., what's in it for me/us?)

6. Other query.

Using this information I generate a variable which summarises the number of positive responses in relation to the six queries above. This variable can take one of three values; the variable is equal to zero if the survey respondent did not raise any of the issues, it is equal to one if they respond 'yes' to at most one of the issues and is equal to two if the survey respondent raises two or more issues. One would expect that the more issues raised by the survey respondent, the less likely they are to be present in the next wave of the survey. Similar to the instrument used to control for initial conditions I test the validity of the retention instrument in Section 5.5.1.

31 This information is collected at the household level and is answered by one individual in the household (if living in a two person household). 
Table 2. Sample respondent queries regarding survey by initial poverty status

\begin{tabular}{lccc}
\hline \hline Poverty status $_{t-1}$ & Raised no queries $_{t-1}$ & Raised 1 query $_{t-1}$ & Raised $>1$ query $_{t-1}$ \\
\hline Poor $_{t-1}$ & $77.7 \%$ & $16.9 \%$ & $5.2 \%$ \\
Non-poor $_{t-1}$ & $81 \% \%^{* * *}$ & $15.4 \%$ & $3.5 \% \%^{* * *}$ \\
\hline \hline
\end{tabular}

Notes: Proportions may add up to more than 1 due to rounding. Statistical differences determined using an independent sample $t$-test assuming unequal variances (by poverty status). Null hypothesis assumes there is no difference between groups. *, **, *** indicate test results that are significant at the $10 \%, 5 \%$ and $1 \%$ levels, respectively.

Table 2 highlights the extent to which individuals raise such queries at the time of their interview conditional on their poverty status at $t-1$. The estimation strategy requires pooling waves of the survey and implies I have repeated observations of the same individual and household. Therefore the results in Table 2 describe the characteristics for only the first two-wave panel, i.e. $t-1$ in Table 2 refers to wave 2 or the calendar year 2010/2011.32

Table 2 indicates approximately $20 \%$ of non-poor and poor households raise at least one query relating to the survey. Table 2 also indicates conditional on initial poverty status there are statistical differences in the mean proportion of queries raised. A priori there is no clear pattern or relationship one would expect between poverty status and retention probability; except perhaps that poor households might be more interested in receiving a financial incentive for taking part in the survey. The results from Table 2 indicate that a slightly higher proportion of this group does ask more queries in general and that this effect is statistically significant for $>1$ query. In terms of financial incentives, for this sample only a very low proportion of households raised this query ( $1 \%$ and $1.5 \%$ of non-poor and poor households, respectively). ${ }^{33}$

\subsection{Descriptive statistics}

\subsubsection{Characteristics}

Table 3 shows the mean value of each individual characteristic used in the model conditional on an individual's poverty status at $t-1$. The sample has been restricted to individuals in the first two-wave consecutive panel, i.e. $t-1$ in Table 3 refers to wave 2 or the calendar year 2010/2011.34

Table 3 indicates that there are significant differences in the observable economic and sociodemographic characteristics of individuals, conditional on their poverty status. In non-poor households, a higher proportion of individuals are younger, male and married. These individuals live in households where a higher proportion of HoHs hold a degree, have two or more non-state pensions, have income from sources other than their pension, self-report a higher level of health and report a higher level

32 The results for the waves 3 and 4 panel are very similar.

33 The difference between these two is not significant at the $5 \%$ level.

34 The individual characteristics for the pair of waves 3-4 are very similar. 
Table 3. Comparison of individual and household characteristics at wave 2 by poverty status

\begin{tabular}{|c|c|c|}
\hline & Poor $_{t-1}$ & Non-poor ${ }_{t-1}$ \\
\hline \multicolumn{3}{|l|}{ Individual characteristic $_{t-1}$} \\
\hline Age & 75 & $74 * * *$ \\
\hline Male & 0.35 & $0.42 * * *$ \\
\hline Single & 0.06 & 0.06 \\
\hline Married & 0.44 & $0.59 * * *$ \\
\hline Divorced & 0.13 & $0.09 * * *$ \\
\hline Widowed & 0.37 & $0.26 * * *$ \\
\hline \multicolumn{3}{|l|}{$H o H$ characteristics $_{t-1}$} \\
\hline Father had a qualification or degree & 0.13 & $0.16 * * *$ \\
\hline Age & 76 & $74 * * *$ \\
\hline Degree & 0.03 & $0.14 * * *$ \\
\hline Higher degree & 0.05 & $0.12 * * *$ \\
\hline A-level & 0.11 & $0.14 * * *$ \\
\hline GCSE & 0.12 & 0.12 \\
\hline Other qualification & 0.19 & $0.15^{* * *}$ \\
\hline No qualification & 0.50 & $0.32 * * *$ \\
\hline Male & 0.50 & $0.65^{* * *}$ \\
\hline Owns home outright & 0.79 & $0.73^{* * *}$ \\
\hline Owns home with mortgage & 0.04 & 0.04 \\
\hline Local authority housing & 0.08 & $0.11 * * *$ \\
\hline Housing association & 0.05 & $0.08 * * *$ \\
\hline Renting & 0.05 & $0.04 * * *$ \\
\hline Excellent health & 0.03 & $0.07 * *$ \\
\hline Very good health & 0.22 & $0.25 * * *$ \\
\hline Good health & 0.30 & $0.28 * *$ \\
\hline Fair health & 0.30 & $0.25 * * *$ \\
\hline Poor health & 0.11 & $0.15 * * *$ \\
\hline Longstanding illness/disability & 0.40 & $0.37 * * *$ \\
\hline Excellent health and limiting illness/disability & 0.01 & 0.02 \\
\hline Very good health and limiting illness/disability & 0.08 & 0.09 \\
\hline Good health and limiting illness/disability & 0.16 & 0.17 \\
\hline Fair health and limiting illness/disability & 0.24 & $0.21 * * *$ \\
\hline Poor health and limiting illness/disability & 0.11 & $0.15^{* * *}$ \\
\hline Not in receipt of disability income benefit & 0.91 & $0.75 * * *$ \\
\hline In receipt of Incapacity/severe disablement benefit & 0.05 & $0.14^{* * *}$ \\
\hline In receipt of attendance or carers allowance & 0.04 & $0.11 * * *$ \\
\hline Cares for someone in household & 0.04 & $0.07 * * *$ \\
\hline $\mathrm{N}$ & 1,939 & 5,136 \\
\hline \multicolumn{3}{|l|}{$H o H$ characteristics t $_{t-1}$} \\
\hline Lives in North East or West & 0.23 & 0.22 \\
\hline Lives in East or West Midlands & 0.18 & $0.14^{* * *}$ \\
\hline Lives in London and South East & 0.15 & $0.19 * * *$ \\
\hline Lives in East of England & 0.07 & $0.09 * *$ \\
\hline Lives in South West and Wales & 0.18 & 0.19 \\
\hline Lives in Scotland & 0.08 & $0.10 * *$ \\
\hline Lives in Northern Ireland & 0.09 & $0.07 * * *$ \\
\hline Financial situation: living comfortably & 0.26 & $0.44 * * *$ \\
\hline
\end{tabular}


Table 3 (cont.)

\begin{tabular}{lll}
\hline \hline & Poor $_{t-1}$ & Non-poor $_{t-1}$ \\
\hline Financial situation: Doing alright & 0.35 & $0.32^{*}$ \\
Financial situation: Just about getting by & 0.34 & $0.21^{* * *}$ \\
Financial situation: Finding it quite difficult & 0.03 & $0.02^{* * *}$ \\
Financial situation: Finding it very difficult & 0.01 & 0.01 \\
State pension (\& pension credit) or no pensions & 0.34 & $0.19^{* * *}$ \\
One non-state pension & 0.58 & $0.63^{* * *}$ \\
Two or more non-state pensions & 0.08 & $0.17^{* * *}$ \\
No sources of non-pension income & 0.52 & $0.44^{* * *}$ \\
Investment income & 0.46 & $0.54^{* * *}$ \\
Private benefit income and misc. income & 0.006 & 0.007 \\
Investment, private benefit and misc. income & 0.004 & $0.01^{* * *}$ \\
$N$ & 1,939 & 5,136 \\
\hline \hline
\end{tabular}

Notes: Proportions may add up to more than 1 due to rounding. Statistical differences determined using an independent sample $t$-test assuming unequal variances. Null hypothesis assumes there is no difference between groups. ${ }^{*}, * *, * * *$ indicate test results that are significant at the $10 \%, 5 \%$ and $1 \%$ levels, respectively.

of satisfaction with their current financial status compared with individuals who are poor. Table 3 also shows that in non-poor households a higher proportion of HoHs had a father who held a formal qualification or degree.

Social benefit income has a strong impact on pensioner's income, particularly if individuals have some form of physical or mental disability. Individuals are entitled to carers or attendance allowance if they are physically or mentally disabled and require assistance with care. Therefore it is not surprising that a higher proportion of individuals in nonpoor households have a $\mathrm{HoH}$ who has caring responsibilities. Similarly individuals who have a mental or physical disability are entitled to various benefits to help support them; hence it is not surprising to find a higher proportion of non-poor individuals who report having a limiting illness or disability and are in receipt of disability benefits. The fact that I do not control for the costs associated with such disabilities or illnesses implies I may be underestimating the true level of poverty among pensioners, and therefore also masking the standard of living experienced by this group of individuals.

Finally, there are differences in housing tenure conditional on poverty status; the proportion of HoHs who report living in local authority housing or in a housing association is higher among those living in non-poor households; however, this is likely to be related to receiving housing benefit. For example, 69\% (36\%) of non-poor (poor) individuals who report living in local authority housing or in a housing association are in receipt of housing benefit, highlighting the significant influence that state benefits can have on determining the income position of pensioners.

\subsection{Pensioner income, income mobility and an individual's standard of living}

Prior to analysing low-income dynamics among pensioners it worth considering how this group of individuals is spread across the entire income distribution, that way it is 


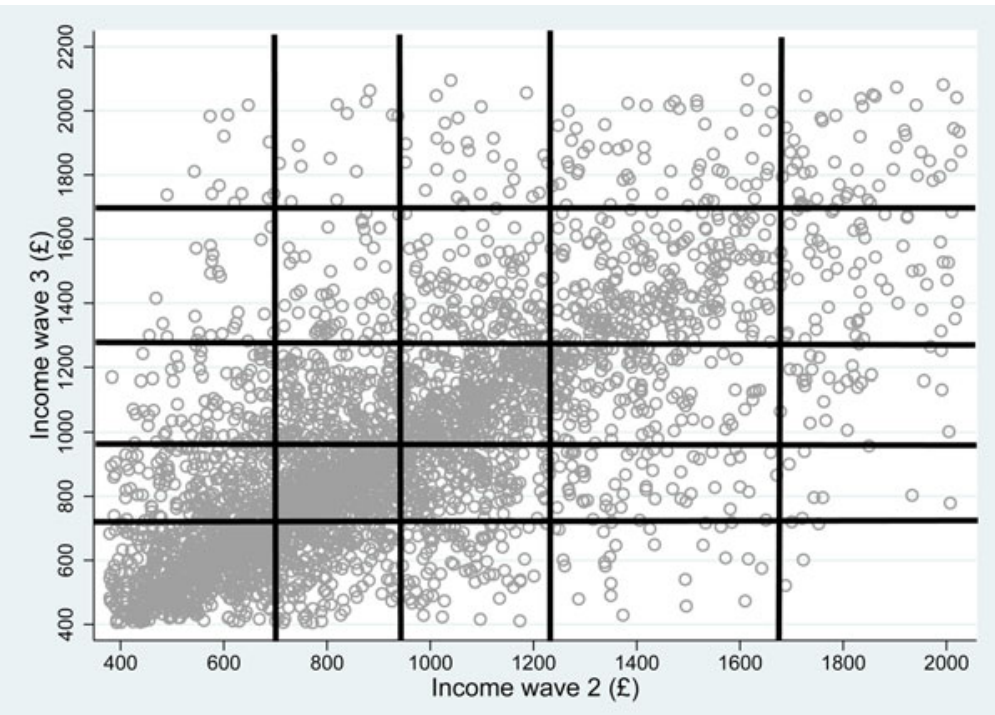

Figure 1. (colour online) Quintile income position among pensioners in waves 2 and 3.

Notes: Income refers to monthly household net equivalised income which has been adjusted to account for inflation (2005 prices).

possible to interpret the estimation results in a wider context. Figure 1 depicts a scatterplot of equivalised real pensioner household income pairs for each individual in the wave $2-3$ sample.

Each of the black lines defines the threshold which corresponds to the AHC quintile position in the relevant wave-income distribution, for example an individual is in the bottom quintile of the AHC income distribution at wave 2 if their equivalised household income is below $£ 693$ (2005 prices). ${ }^{35}$ From Figure 1 it is clear a large proportion of individuals are in the middle-lower end of the AHC income distribution irrespective of survey wave. For example, at wave 2 (3) $59 \%$ (58\%) of pensioners were classified as being in the bottom 2 quintiles of the $\mathrm{AHC}$ income distribution. ${ }^{36}$

The data in Figure 2 are identical to Figure 1; however instead of income quintiles, it compares income pairs relative to the AHC poverty threshold at each wave. The $45^{\circ}$ line corresponds to the case where there is no income mobility between the survey waves.

Figure 2 highlights that a significant proportion of the sample persists in poverty across both survey waves; however, there is also individuals who experience significant changes in their income position, represented by circles above and below the $45^{\circ}$ line. Pensioners both exit and enter poverty each year; for example among pensioners whose income is observed at waves 2 and 3: $10.10 \%$ enter poverty and $31.75 \%$ exit

35 Using a representative household panel survey such as Understanding Society means it is possible to account for the survey design and use the full sample to generate poverty thresholds and quintile position in the income distribution. This is undertaken using the svy suite of commands in Stata.

36 The wave 3 statistic accounts for the fact that $14 \%$ of the sample attrited between waves 2 and 3 of the survey. 


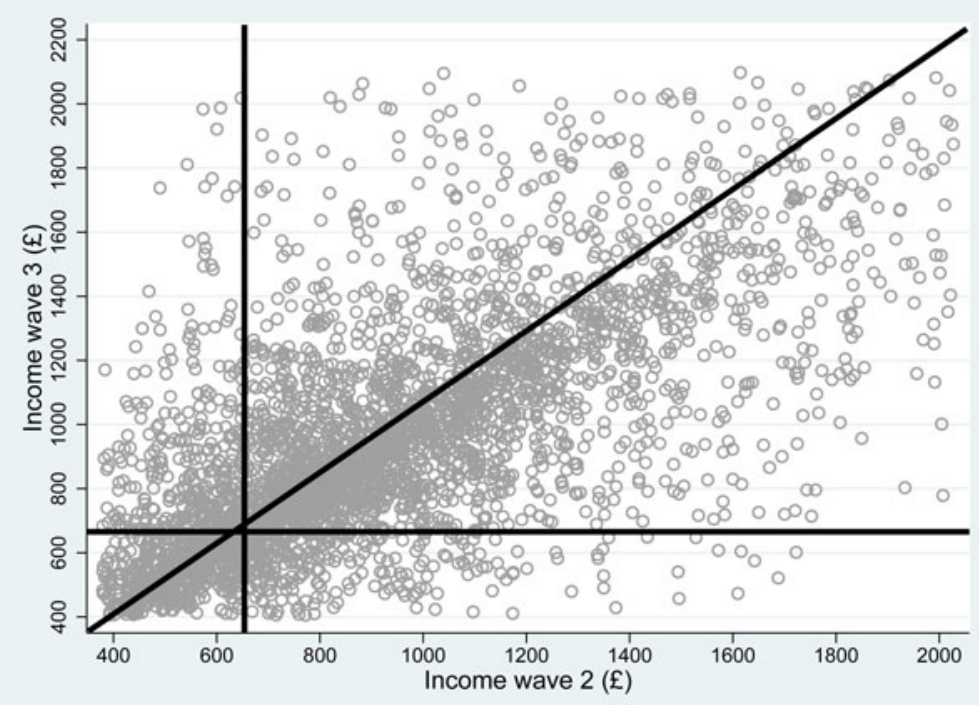

Figure 2. (colour online) Scatterplot of waves 2 and 3 income versus poverty threshold.

Notes: Income refers to monthly household net equivalised income which has been adjusted to account for inflation (2005 prices).

poverty. The large differences are due to the fact that the initial pool of non-poor pensioners is far bigger than the pool of initially poor pensioners.

However, does escaping poverty correspond to an improvement in an individual's standard of living? We have already seen that state benefits, in particular disability related benefits, can heavily influence the income position of a pensioner. For example, an increase in income may be due to becoming disabled and claiming particular benefits which boost income; but undoubtedly mean an individual's standard of living is likely to have decreased without even accounting for the higher care costs incurred. Section 5 explores the changes in the sources of individual-level income among pensioners (by poverty status) in order to understand what is driving the changes reflected in Figures 1 and 2. Jenkins (2011) shows a similar pattern exists for working age households, a priori one may have expected less volatility in incomes across a single survey-wave among pensioner households given their lifestage and relatively stable income sources; this underlines the importance of understanding the factors driving such dynamics.

\section{Estimation results and sensitivity analysis}

\subsection{Estimation}

Estimation is carried out using the STATA $^{\mathrm{TM}}$ commands mdraws and mvnp (for more information see Cappellari and Jenkins, 2003, 2006). ${ }^{37}$ Probabilities from the trivariate standard normal distribution function are derived using simulation methods based

\footnotetext{
37 The model requires the use of the STATA $^{\text {TM }}$ code in Section 3.5 of Cappellari and Jenkins (2006).
} 
on the GHK simulator (Gourieroux and Monfort, 1997) with antithetic Halton draws (200 per equation). ${ }^{38}$ The estimation strategy requires pooling multiple waves of survey data. This implies our sample consists of repeated observations on the same individual and therefore the IID assumption is violated. I follow Cappellari and Jenkins (2004) and adjust standard errors using a robust variance estimator by clustering individuals to households to which they belonged in at the first wave of observation. This so-called robust variance estimator allows for arbitrary correlations between observations within the same sample cluster whilst assuming independence across clusters (Jenkins, 2011, 341). In practice, the estimation of equations (1)-(3) is carried out simultaneously however for the purpose of exposition I discuss each equation in turn and then go on to discuss the cross equation correlations.

\subsection{Initial poverty status}

Table 4 describes the impact of individual and $\mathrm{HoH}$ characteristics on determining initial poverty status. The marginal effect is calculated as the change in the probability of being in poverty relative to the reference individual. The reference individual is defined as an individual whose own age and their HoH's age is equal to the median values in the sample (73 and 74, respectively). In the case of categorical or dummy variables, the marginal effect is calculated as a unit change in a particular characteristic whilst setting all other characteristics equal to zero. For continuous variables (age and $\mathrm{HoH}$ age) the marginal effect is calculated as a change from the median to the 75th percentile in the relevant age distribution.

Table 4 shows that being a female pensioner raises the probability of being poor, for example at $t-1$ (wave 2) the median monthly income among male and female single person households was $£ 837$ and $£ 766$ respectively. This effect is stronger at the individual level rather than the $\mathrm{HoH}$ level, however, both characteristics are statistically significant. This is likely to be partly driven by the significant proportion of single pensioner households in the sample. Further, given the cohort(s) of individuals in the sample it is likely the labour market participation histories of male and female sample respondents is different (with males having stronger labour force attachment), even after accounting for the fact that certain pensions schemes entitle widow's some fraction of their deceased spouse's pension.

Similarly marital status also influences initial poverty status, relative to having been single and never married an individual who self-reports themselves as being married is 6.6 percentage points less likely to be in poverty holding all else constant. This result is intuitive and reflected in the OECD equivalence scale, couples can exploit economies of scale in (for example) consumption and energy costs. On the other hand, individuals who have divorced or separated are 5.1 percentage points more likely to be in poverty holding all else constant, however, this effect is only significant at the $10 \%$ level.

38 Halton draws have been shown to have good multidimensional coverage properties (Train, 2009; Cappellari and Jenkins, 2003). I drop the first ten initial sequence elements for each equation which is greater than the highest prime number (5) used to generate the sequences. 
Table 4. Model estimates of initial poverty status

\begin{tabular}{|c|c|c|}
\hline Variable & M.E. & Coefficient (S.E.) \\
\hline \multicolumn{3}{|l|}{ Individual } \\
\hline Age & -0.0039 & $-0.00004(0.007)$ \\
\hline Male & $-0.019 * * *$ & $-0.07(0.028)$ \\
\hline Married & $-0.068 * * *$ & $-0.27(0.07)$ \\
\hline Divorced & $0.034^{*}$ & $0.17(0.078)$ \\
\hline Widowed & 0.0009 & $0.03(0.067)$ \\
\hline \multicolumn{3}{|l|}{$\mathrm{HoH}$} \\
\hline Father educated & $-0.026^{* *}$ & $-0.148(0.05)$ \\
\hline Age & $0.020 * *$ & $-0.02(0.007)$ \\
\hline Male & -0.016 & $-0.12(0.05)$ \\
\hline Other higher degree & 0.07 & $0.29(0.09)$ \\
\hline A-level & $0.24 * * *$ & $0.76(0.08)$ \\
\hline GCSE & $0.26^{* * *}$ & $0.84(0.08)$ \\
\hline Other qualification & $0.263 * * *$ & $0.93(0.08)$ \\
\hline No qualification & $0.30 * * *$ & $0.94(0.08)$ \\
\hline Owns home with mortgage & $-0.048^{* * *}$ & $-0.18(0.09)$ \\
\hline Local authority housing & $-0.13 * * *$ & $-0.89(0.06)$ \\
\hline Housing association & $-0.14 * * *$ & $-0.92(0.07)$ \\
\hline Renting & $-0.05 * * *$ & $-0.21(0.08)$ \\
\hline Health: Very good & $0.04 *$ & $0.14(0.08)$ \\
\hline Health: Good & 0.037 & $0.13(0.08)$ \\
\hline Health: Fair & $0.09 * * *$ & $0.29(0.10)$ \\
\hline Health: Poor & 0.01 & $0.04(0.23)$ \\
\hline Longstanding illness/disability & $0.04 * * *$ & $0.15(0.04)$ \\
\hline Very good health and limiting illness/disability & -0.039 & $-0.15(0.16)$ \\
\hline Good health and limiting illness/disability & -0.04 & $-0.15(0.15)$ \\
\hline Fair health and limiting illness/disability & -0.05 & $-0.18(0.16)$ \\
\hline Poor health and limiting illness/disability & -0.025 & $-0.08(0.26)$ \\
\hline In receipt of Incapacity/severe disablement benefit & $-0.157 * * *$ & $-0.86(0.07)$ \\
\hline In receipt of attendance or carers allowance & $-0.165 * * *$ & $-0.95(0.07)$ \\
\hline East and West Midlands & 0.02 & $0.08(0.07)$ \\
\hline London and South East & $-0.03^{*}$ & $-0.11(0.07)$ \\
\hline East of England & -0.01 & $-0.06(0.07)$ \\
\hline South West and Wales & -0.02 & $-0.07(0.06)$ \\
\hline Scotland & -0.02 & $-0.08(0.07)$ \\
\hline Northern Ireland & $-0.08 * * *$ & $-0.36(0.08)$ \\
\hline FS: 'Doing alright' & $0.01 * * *$ & $0.35(0.04)$ \\
\hline FS: 'Just about getting by’ & $0.19 * * *$ & $0.57(0.05)$ \\
\hline FS: 'Finding it quite difficult' & $0.18 * * *$ & $0.55(0.10)$ \\
\hline FS: 'Finding it very difficult' & $0.30^{* * *}$ & $0.84(0.16)$ \\
\hline 1 Employer/occupational pension & $-0.11 * * *$ & $-0.48(0.04)$ \\
\hline$>1$ Employer/occupational pension & $-0.16^{* * *}$ & $-0.93(0.06)$ \\
\hline Investment income & 0.017 & $0.063(0.039)$ \\
\hline Private benefit income and misc. income & -0.09 & $-0.38(0.133)$ \\
\hline Investment, private benefit and misc. income & -0.10 & $-0.45(0.131)$ \\
\hline Cares for another in household & $-0.068 * * *$ & $-0.27(0.09)$ \\
\hline Data from wave $2-3$ block & 0.007 & $0.03(0.02)$ \\
\hline Intercept & N/A & $-2.07(0.24)$ \\
\hline
\end{tabular}


Table 4 (cont.)

\begin{tabular}{lcc}
\hline \hline Variable & M.E. & Coefficient (S.E.) \\
\hline \multirow{2}{*}{ Log-likelihood } & $-15,205.078$ & \\
$\chi_{22}^{2}$ & 314.27 & \\
$N$ & 12,904 & \\
\hline \hline
\end{tabular}

Notes: Base groups are degree, owns home outright, Health: excellent, North East and West of England, Financial situation: living comfortably, State pension and/or Pension Credit, No disability benefits, No non-pension income sources. ${ }^{*}, * * * * *$ indicate coefficient is significant at the $10 \%, 5 \%$ and $1 \%$ level, respectively.

Educational attainment plays an important role in determining initial poverty status. Table 4 indicates that relative to university degree holders all other groups are significantly more likely to be in poverty. The magnitude of the marginal effect is large and monotonically increases the lower the level of educational attainment attained; for example having no qualifications increases the likelihood of being poor in $t-1$ by 30 percentage points holding all else constant.

Table 4 shows that the HoH's father's educational attainment also plays an important role in determining the likelihood of being in poverty. The marginal effect of having a father who left school with a recognisable qualification or degree reduces the probability of an individual being in poverty by 3.4 percentage points. This result indicates that paternal educational attainment is 'relevant' in a statistical sense and satisfies one of the conditions for being a suitable instrument to control for initial conditions; a body of research has shown parent's educational attainment is important in explaining the correlation in the intergenerational transmission of earnings and wealth (see inter-alia Shin and Solon, 2011). A raw tabulation based on the sample data indicates that $23 \%$ of HoH's whose father left school with a recognised qualification or degree had a degree themselves (which has been shown to be important in determining initial poverty status); whereas for HoH's whose father left school with no recognisable qualification this figure is only $9.7 \%$.

Table 4 highlights the importance of having an occupational or employer pension compared with relying solely on state pension income alone. ${ }^{39}$ Unsurprisingly, the level of savings made for retirement has been found to be an important determinant of retirement living standards (Crawford and O'Dea, 2014). The marginal effect of having one occupational or employer pension reduces the probability of being in initial poverty by 11 percentage points. Similarly having two or more occupational or employer pensions reduces the probability being in initial poverty, the magnitude of this effect is approximately 1.6 times that of having one occupational/employer pension. The introduction of auto-enrolment in to a workplace pension in 2012 is example of how to increase provisions for retirement, however such a policy will not

39 The base group also includes individuals who report being in receipt of state pension and pension credit only and also a very small proportion of the sample who reported that they were not in receipt of any of the types of pensions asked mentioned in the survey; however a high proportion $(>50 \%)$ of this group were in poverty in $t-1$. 
address pensioner poverty among current retirees or among individuals close to retirement age.

Benefit income is another important source of income for pensioners. Pensioners may be entitled to disability or incapacity benefit (although both are being replaced with Employment Support Allowance), in order to be eligible an individual must suffer from a particular physical or mental impairment and this may be formally verified in order to determine the level of support and benefit entitlement. An individual who lives in a household where the $\mathrm{HoH}$ reports being in receipt of this benefit is 15.7 percentage points less likely to be poverty, highlighting the significant impact such a benefit can have on determining an individual's income position. Another type of benefit which can impact a pensioner's income is carers or attendance allowance. An individual who lives in a household where the $\mathrm{HoH}$ reports being in receipt of this benefit is 16.5 percentage points less likely to be in poverty. This raises the issue as to whether an income-based measure such as poverty, which does not account for care costs associated with having a particular disability appropriately measure a pensioner's actual standard of living (Hancock et al., 2015). Moreover, Hancock et al. (2015) show that the prevalence of disabilities among the over $65 \mathrm{~s}$ is concentrated at the lower end of the income distribution.

In addition to pension and benefit income, pensioners are likely to be in receipt of income from other sources, for example from investments made earlier in their lives. An individual who lives in a household where the $\mathrm{HoH}$ reports being in receipt of (1) private benefit and miscellaneous income or (2) investment, private benefit and miscellaneous income relative to an individual who lives in household where the $\mathrm{HoH}$ reports not being in receipt of any of these income sources is 9.17 and 10.41 percentage points less likely to be in poverty.

Alongside income, pensioners hold a significant amount of their total wealth in housing (Lowe et al., 2012). Therefore housing tenure is an important characteristic to control for. Table 4 highlights that relative to respondents who own their house outright, reporting any other kind of housing tenure corresponds to a reduction in the probability of being in initial poverty. Whilst this result might seem surprising it is worth noting that the measure of poverty used in this paper accounts for housing costs. Moreover, various social benefits that pensioners are entitled to are means tested. Therefore individuals in local authority housing or living in a housing association may be in receipt of other benefits (which reduce the likelihood of being in poverty), for example $24.25 \%(20.32 \%)$ of individuals who reported living in local authority (a housing association) accommodation were in receipt of incapacity benefit; whereas only $8.26 \%$ of outright homeowners reported being in receipt of this benefit. ${ }^{40}$

Previous studies have found a strong correlation between health and income (see inter-alia Stronks et al., 1997; Deaton, 1999). Table 4 shows that individuals who report being in fair health (relative to excellent) raise their likelihood of being in poverty by 9 percentage points, holding all else constant. However individuals who report of poor

40 Understanding Society does not collect annual information on housing wealth and therefore it is not possible to control for the value of an individual's home, moreover such data are likely to contain a lot measurement error. 
health are not statistically more likely to be in poverty. This result is likely to be due to the fact that individuals who report being in poor health are more likely to be in receipt of a particular benefit(s) such as disability benefit, and Table 4 shows that this reduces the likelihood of being in poverty. Indeed, over 35\% of HoHs who report their health as 'poor' are in receipt of incapacity or severe disability benefit, whereas only $1.16 \%$ of HoHs who report being in excellent health report claiming these benefits.

Alongside measures of self-reported health UKHLS also asks individuals whether they have a longstanding illness or disability; a positive response increases the probability of being in initial poverty by 4.1 percentage points. ${ }^{41,42}$ In order to determine the joint effect of self-reported health and having a limiting illness I interact these covariates, however the coefficient estimates are not statistically significant.

Understanding Society also contains information about caring responsibilities in the household. Specifically it asks whether an individual cares for a sick, disabled or elderly individual in the household. A positive response leads to a reduction in the probability of being in initial poverty by 6.8 percentage points. Again, this is likely to be related to the fact that these individuals are likely to be in receipt of Attendance Allowance or Carer's Allowance which increases individual and therefore household income, however, as already highlighted such benefits do not fully account for the significant care costs associated with the disability (Hancock et al., 2015).

UKHLS also asks respondents to assess their contemporaneous financial situation. Table 4 suggests that relative to individuals who report 'living comfortably' and individuals who report a lower level of subjective financial situation are significantly more likely to be in poverty. Indeed, this effect is monotonically increasing the lower the level of financial situation reported; for example an individual living in a household where the $\mathrm{HoH}$ reports that they are finding it 'very difficult' is 30 percentage points more likely to be in poverty at $t-1$ holding all else constant.

\subsection{Sample retention}

Table 5 shows the effect particular individual and $\mathrm{HoH}$ characteristics have on the probability of attriting from the survey in period $t$, conditional on having been in the survey at $t-1$.

At the individual level Table 5 indicates that older individuals are more likely to attrit from the survey holding all else constant; the marginal effect of increasing an individual's age from the sample median (73) to the $75^{\text {th }}$ percentile increases the probability of attriting from the survey by 3.3 percentage points.

Individuals who report being married are less likely to attrit from the sample relative to single individuals; on the other hand the marginal effect of being a divorcee or widow/widower does not have a significant effect on the probability of attriting from survey relative to being single.

41 A longstanding illness or disability is defined as a condition that has troubled the respondent for at least 12 months.

42 It could be that such impairments may have hindered employment however the survey does not ask how long the individual has had this impairment and if it affects paid work (either contemporaneous or in the past). 
Table 5. Model estimates of survey retention status

\begin{tabular}{lcc}
\hline \hline Variable & M.E. & Coefficient (S.E.) \\
\hline Individual & & \\
Age & $-0.033^{* * *}$ & $-0.031(0.006)$ \\
Male & 0.003 & $0.019(0.029)$ \\
Married & $-0.023^{* *}$ & $-0.13(0.069)$ \\
Divorced & 0.007 & $0.074(0.075)$ \\
Widowed & -0.003 & $-0.017(0.06)$ \\
HoH & & \\
Age & 0.007 & $0.010(0.007)$ \\
Male & -0.005 & $-0.03(0.051)$ \\
Owns home with mortgage & -0.015 & $-0.09(0.083)$ \\
Local authority housing & $-0.018^{* *}$ & $-0.11(0.053)$ \\
Housing association & $-0.025^{* * *}$ & $-0.15(0.059)$ \\
Renting & $-0.024^{*}$ & $-0.14(0.08)$ \\
Cares for another in household & -0.013 & $-0.08(0.070)$ \\
Longstanding illness/disability & -0.005 & $-0.03(0.040)$ \\
Health: Very good & -0.012 & $-0.08(0.078)$ \\
Health: Good & -0.005 & $-0.03(0.078)$ \\
Health: Fair & $-0.0473^{* * *}$ & $-0.27(0.08)$ \\
Health: Poor & $-0.105^{* * *}$ & $-0.51(0.08)$ \\
Raised 1 query & $-0.036^{* * *}$ & $-0.21(0.04)$ \\
Raised >1 query & $-0.029^{*}$ & $-0.18(0.10)$ \\
1 Employer/occupational pension & $0.017^{* *}$ & $0.13(0.04)$ \\
$>1$ Employer/occupational pension & $0.019^{* *}$ & $0.14(0.05)$ \\
Data from wave 2-3 block & $-0.013^{* *}$ & $-0.077(0.034)$ \\
Intercept & $\mathrm{N} / \mathrm{A}$ & $2.92(0.20)$ \\
Log-likelihood & $-15,205.078$ & \\
$\chi_{22}^{2}$ & 314.27 & \\
N & 12,904 & \\
\hline \hline & & \\
\hline
\end{tabular}

Notes: Base groups are degree, owns home outright, Health: excellent, North East and West of England, Financial situation: living comfortably, State pension and/or Pension Credit. $*, * *, * * *$ indicate coefficient is significant at the $10 \%, 5 \%$ and $1 \%$ level, respectively.

At the $\mathrm{HoH}-\mathrm{level}$ housing tenure is important in determining survey retention. HOHs who own their own home are significantly more likely to remain in the survey relative to individuals who live in local authority housing or in a housing association. This finding is consistent with attrition patterns found in other European longitudinal household panel surveys (Watson, 2002).

Table 5 suggests that self-reported health is an important factor in attriting from the survey. HoHs who reported being in fair or poor health were 4.9 and 10.8 percentage points respectively more likely to attrit between $t-1$ and $t$, relative to $\mathrm{HoHs}$ who reported having excellent health holding all else constant.

Sources of income are also important in determining survey attrition. Table 5 shows that a $\mathrm{HoH}$ who did not rely solely on state pension and/or pension credit as their only source of income, that is to say individuals who reported being in receipt of one or more private or occupational pensions were significantly more likely to remain in the survey. 
Finally, Table 5 highlights the importance of controlling for particular aspects of the survey interview, as summarised in Section 4.3. Living in a household where one survey query was raised leads to an increase in the probability of attriting from the sample between period $t-1$ and $t$ by 3.7 percentage points. Raising more than one query also raised the probability of attriting by 3.1 percentage points; however this effect was only significant at the $10 \%$ level.

\subsection{Conditional poverty status}

The first-order Markov approach followed in this study formally accounts for the possibility that individual and $\mathrm{HoH}$ characteristics may have a differential impact on conditional poverty status. One way to test whether this is true is to test for evidence of state dependence. Aggregate State Dependence (ASD) is the difference between poverty persistence and poverty entry among individuals who were initially poor and non-poor, respectively. The estimate of ASD calculated for the sample is 0.587 among all individuals present at $t-1$. This figure is in line with previous research estimating poverty dynamics using a first-order Markov framework applied to longitudinal household panel data; Cappellari and Jenkins (2004) estimate ASD of 0.526 based on a sample of British individuals aged between 25 and 59, Buddelmeyer and Verick (2008) estimate ASD of 0.57 based on their sample of Australian individuals aged between 25 and 55. More recently Fusco and Islam (2012) compute an estimate of ASD of 0.65 using the Luxembourgish component of the EU-SILC. The reason the estimate of ASD is higher in this study relative to previous studies using longitudinal British data is due to the fact that these studies focus on working age poverty dynamics, whereas it has been shown that pensioners have higher persistent poverty rates relative to the working age population (Jenkins and Rigg, 2001; Cappellari and Jenkins, 2004; DWP, 2015).

Whilst ASD is a useful measure of the differences between poverty persistence and poverty entry it does not account for individual heterogeneity and the fact that there might be scarring effects from being in poverty. Genuine State Dependence (GSD) on the other hand does account for individual (observable and unobservable) differences which may affect poverty persistence and poverty entry; Cappellari and Jenkins (2004) show that one test for GSD in the case of a first-order Markov framework is to test whether the covariates used to explain poverty entry and persistence have an identical effect on conditional poverty status at $t$ irrespective of initial poverty status at $t-1\left(H_{0}: \theta_{1}=\theta_{2}\right)$. A test of this based on the estimation sample suggests that $H_{0}$ could not be rejected at conventional levels of significance (Prob $>\chi^{2}=0.72$ ). This finding is in contrast to previous studies of poverty dynamics which do find significant evidence of GSD however the focus of those studies is on working age poverty (see inter-alia Cappellari and Jenkins, 2004; Biewen, 2009; Fusco and Islam, 2012). The strong connection between the state and pensioner incomes is likely to mitigate the extent of scarring effects resulting from being in poverty.

\subsubsection{Covariate effects conditional on being initially poor}

Table 6 shows that individuals who are divorced are significantly more likely to persist in poverty relative to individuals who have always been single. On the other hand, the 
Table 6. Model estimates of conditional poverty status

\begin{tabular}{|c|c|c|c|c|}
\hline \multirow[b]{2}{*}{ Variable } & \multicolumn{2}{|r|}{ Poor } & \multicolumn{2}{|c|}{ Non-poor } \\
\hline & M.E. & $\begin{array}{l}\text { Coefficient } \\
\text { (S.E.) }\end{array}$ & M.E. & $\begin{array}{l}\text { Coefficient } \\
\text { (S.E.) }\end{array}$ \\
\hline \multicolumn{5}{|l|}{ Individual } \\
\hline Age & 0.008 & $-0.003(0.01)$ & 0.003 & $0.006(0.009)$ \\
\hline Male & -0.01 & $-0.003(0.07)$ & -0.006 & $-0.076(0.05)$ \\
\hline Married & 0.04 & $0.10(0.115)$ & -0.01 & $-0.12(0.09)$ \\
\hline Divorced & $0.09 * *$ & $0.23(0.114)$ & 0.008 & $0.09(0.09)$ \\
\hline Widowed & 0.04 & $0.09(0.101)$ & 0.005 & $0.05(0.08)$ \\
\hline \multicolumn{5}{|l|}{$\mathrm{HoH}$} \\
\hline Age & 0.004 & $-0.0005(0.013)$ & -0.023 & $-0.0004(0.009)$ \\
\hline Male & -0.017 & $0.008(0.105)$ & -0.0028 & $-0.014(0.07)$ \\
\hline Other higher degree & 0.093 & $0.17(0.17)$ & $0.030 * * *$ & $0.23(0.106)$ \\
\hline A-level & 0.093 & $0.14(0.18)$ & $0.069 * * *$ & $0.45(0.10)$ \\
\hline GCSE & 0.15 & $0.26(0.19)$ & $0.056 * * *$ & $0.368(0.10)$ \\
\hline Other qualification & 0.127 & $0.22(0.18)$ & $0.066^{* * *}$ & $0.43(0.10)$ \\
\hline No qualification & 0.127 & $0.21(0.18)$ & $0.089 * * *$ & $0.54(0.10)$ \\
\hline Owns home with mortgage & 0 & $0.02(0.14)$ & -0.015 & $-0.13(0.11)$ \\
\hline Local authority housing & $-0.175 * *$ & $-0.38(0.16)$ & -0.018 & $-0.15(0.09)$ \\
\hline Housing association & -0.136 & $-0.27(0.18)$ & $-0.025^{* *}$ & $-0.25(0.10)$ \\
\hline Renting & -0.038 & $-0.08(0.13)$ & $-0.020 * *$ & $-0.22(0.11)$ \\
\hline Health: Very good & 0.061 & $0.13(0.12)$ & -0.004 & $0.086(0.098)$ \\
\hline Health: Good & 0.049 & $0.05(0.11)$ & -0.003 & $0.057(0.09)$ \\
\hline Health: Fair & 0.005 & $0.01(0.12)$ & 0.030 & $0.097(0.108)$ \\
\hline Health: Poor & 0.221 & $-0.04(0.16)$ & -0.016 & $0.06(0.12)$ \\
\hline Longstanding illness/disability & 0.035 & $0.097(0.064)$ & -0.032 & $0.05(0.05)$ \\
\hline $\begin{array}{l}\text { Very good health and limiting } \\
\text { illness/disability }\end{array}$ & -0.053 & $-0.12(0.29)$ & 0.096 & $0.572(0.27)$ \\
\hline $\begin{array}{l}\text { Good health and limiting } \\
\text { illness/disability }\end{array}$ & -0.093 & $-0.21(0.28)$ & 0.0693 & $0.453(0.27)$ \\
\hline $\begin{array}{l}\text { Fair health and limiting illness/ } \\
\text { disability }\end{array}$ & -0.09 & $-0.20(0.29)$ & 0.0243 & $0.199(0.29)$ \\
\hline $\begin{array}{l}\text { Poor health and limiting illness/ } \\
\text { disability }\end{array}$ & -0.291 & $-0.72(0.52)$ & 0.1153 & $0.650(0.39)$ \\
\hline $\begin{array}{l}\text { In receipt of Incapacity/severe } \\
\text { disablement benefit }\end{array}$ & -0.058 & $-0.12(0.14)$ & -0.0177 & $-0.181(0.087)$ \\
\hline $\begin{array}{l}\text { In receipt of attendance or } \\
\text { carers allowance }\end{array}$ & -0.208 & $-0.48(0.18)$ & -0.0156 & $-0.164(0.098)$ \\
\hline East and West Midlands & 0.013 & $0.031(0.08)$ & 0.01 & $0.09(0.07)$ \\
\hline London and South East & $0.067^{*}$ & $0.16(0.09)$ & $-0.015^{*}$ & $-0.16(0.07)$ \\
\hline East of England & -0.033 & $-0.08(0.11)$ & -0.005 & $-0.04(0.09)$ \\
\hline South West and Wales & 0.017 & $0.04(0.08)$ & -0.013 & $-0.12(0.07)$ \\
\hline Scotland & 0.044 & $0.10(0.10)$ & 0.007 & $0.07(0.08)$ \\
\hline Northern Ireland & 0.011 & $0.029(0.12)$ & -0.007 & $-0.07(0.09)$ \\
\hline FS: 'Doing alright' & -0.022 & $-0.062(0.078)$ & $0.013^{*}$ & $0.103(0.06)$ \\
\hline FS: 'Just about getting by' & -0.04 & $-0.127(0.09)$ & $0.035^{* * *}$ & $0.26(0.071)$ \\
\hline FS: 'Finding it quite difficult' & 0.0593 & $0.104(0.16)$ & $0.057 * * *$ & $0.38(0.15)$ \\
\hline FS: 'Finding it very difficult' & -0.094 & $-0.28(0.23)$ & 0.001 & $-0.005(0.24)$ \\
\hline
\end{tabular}


Table 6 (cont.)

\begin{tabular}{|c|c|c|c|c|}
\hline \multirow[b]{2}{*}{ Variable } & \multicolumn{2}{|c|}{ Poor } & \multicolumn{2}{|c|}{ Non-poor } \\
\hline & M.E. & $\begin{array}{l}\text { Coefficient } \\
\text { (S.E.) }\end{array}$ & M.E. & $\begin{array}{l}\text { Coefficient } \\
\text { (S.E.) }\end{array}$ \\
\hline $\begin{array}{l}1 \text { Employer/occupational } \\
\text { pension }\end{array}$ & -0.015 & $-0.0007(0.06)$ & -0.002 & $-0.017(0.046)$ \\
\hline $\begin{array}{l}>1 \text { Employer/occupational } \\
\text { pension }\end{array}$ & -0.039 & $0.009(0.11)$ & $-0.016^{* * *}$ & $-0.22(0.08)$ \\
\hline Investment income & $0.06 * * *$ & $0.152(0.06)$ & -0.0037 & $-0.036(0.053)$ \\
\hline $\begin{array}{l}\text { Private benefit income and } \\
\text { misc. income }\end{array}$ & 0.015 & $0.042(0.25)$ & 0.0122 & $0.106(0.143)$ \\
\hline $\begin{array}{l}\text { Investment, private benefit and } \\
\text { misc. income }\end{array}$ & 0.168 & $0.418(0.31)$ & 0.0096 & $0.084(0.168)$ \\
\hline Cares for another in household & -0.003 & $-0.03(0.17)$ & -0.014 & $-0.19(0.11)$ \\
\hline Data from wave $2-3$ block & -0.0005 & $-0.001(0.05)$ & -0.0191 & $0.07(0.04)$ \\
\hline Intercept & N/A & $0.46(0.49)$ & N/A & $-2.22 * * *(0.31)$ \\
\hline Log-likelihood & \multicolumn{4}{|c|}{$-15,205.078$} \\
\hline$\chi_{22}^{2}$ & \multicolumn{4}{|l|}{314.27} \\
\hline $\mathrm{N}$ & \multicolumn{4}{|l|}{12,904} \\
\hline
\end{tabular}

Notes: Base groups are degree, owns home outright, Health: excellent, North East and West of England, Financial situation: living comfortably State pension and/or Pension Credit, No disability benefits, No non-pension income sources. *,**,*** indicate coefficient is significant at the $10 \%, 5 \%$ and $1 \%$ level, respectively.

marginal effect of living in local authority housing or a housing association reduces the probability of persisting in poverty. This is likely to be related to (changes in) the particular types of benefit income these individuals are claiming (at particular survey waves) relative to individuals in other types of housing tenure.

Table 6 also highlights the importance of education in affecting poverty persistence, even in retirement. Relative to individuals who lived in a household where the $\mathrm{HoH}$ had a degree, lower levels of educational attainment such as 'other or no qualification' increased the probability of being in poverty by 12.7 percentage points. This is also reflected in Table 3, which shows that $15 \%$ of non-poor households have a $\mathrm{HoH}$ with a degree, this figure stands at only $3 \%$ among poor households. There is a strong correlation between educational attainment and career occupation, therefore changes in the sources of income in retirement for example the number and type of pensions an individual is in receipt of, and how this may change between $t-1$ and $t$ imply that increases in income will (on average) be concentrated among individuals with a higher level of educational attainment.

Table 6 highlights the importance of benefit income in determining poverty status. Individuals in receipt of caring or attendance allowance are more than 20 percentage points less likely to persist in poverty relative to individuals who are not in receipt of these benefits. Whilst this reduces the likelihood of persisting in low income it is hard to argue that the standard of living of these individuals has improved from a welfare 
perspective. Finally, individuals who were in receipt of only investment income were significantly more likely to be in poverty relative to individuals who were not in receipt of additional (non-pension) income sources.

Table 6 indicates that relatively few characteristics were statistically significant in the poverty persistence equation, whereas in the equation for initial poverty status there were many more significant covariates. Cappellari and Jenkins (2004) note that the lack of significant results is due to: (1) the framework accounting for the initial conditions problem; and (2) the fact that the number of individuals at risk of poverty persistence is significantly smaller than that at risk of poverty entry, as shown in Table 1.

For individuals who are in poverty at $t-1$ the model estimates imply the probability they remain in this state (i.e., poverty persistence) is 0.69 , this does not change if I restrict the sample to individuals present at $t-1$ and $t$. This finding is of policy relevance: the results suggest that there is a high degree of state dependence in poverty among pensioner households in the UK. However, there are no policies such as job assistance programmes to enable these households to escape poverty in the long run; this may be in part due to the notion that retirement in the UK is considered a permanent exit from the labour market (Kohli, 1991). Previous studies have highlighted the sharp drop in labour supply when individuals approach retirement age in Britain and the lack of partial retirement or unretirement (Blundell et al., 2002; Banks et al., 2006; Kanabar, 2015). Existing policies such as Pension Credit (and its predecessor the Minimum Income Guarantee) aim to supplement an individual's income once they are in poverty, i.e. they are largely reactive policies.

The analysis also indicates that pensioner incomes are heavily influenced by benefit income which does not necessarily lead to a 'welfare improving outcome' in the context of exiting poverty, especially when one factors in additional costs associated with care. Nonetheless, certain income supplementation programmes such as Pension Credit have been shown to increase the net income of the poorest pensioners (Brewer and Emmerson, 2003). Although the authors note that the complexity of the UK benefit system can mean that claiming Pension Credit affects an individual's eligibility for other benefits, and the marginal withdrawal rate can be as high as $91 \% .{ }^{43}$

\subsubsection{Covariate effects conditional on being initially non-poor}

Table 6 highlights that five $\mathrm{HoH}$ characteristics affect the probability of entering poverty: education, housing tenure, subjective financial situation, benefit income and pensions. We discuss each of these in turn.

The likelihood of entering poverty is significantly higher among individuals whose $\mathrm{HoH}$ has a lower level of educational attainment. An individual living in a household where the HoH's highest level of educational attainment is a GCSE or equivalent level

43 The general effect of Pension Credit is to reduce the effective marginal withdrawal rate see Brewer and Emmerson $(2003,91)$. The authors show that the introduction of Pension Credit has an income and substitution effect and its success largely depends on how these effects vary by particular groups of pensioners, and also by differences in the retirement savings behaviour among the current working population (Clark, 2001; Brewer and Emmerson, 2003). 
of education, is 5.6 percentage points more likely to enter poverty relative to a $\mathrm{HoH}$ with a degree. The marginal effect is even higher for HoHs who do not have a formal qualification ( 8.9 percentage points); this is concerning given that $35 \%$ of the sample fall in to this category.

Housing tenure is another important factor in determining whether an individual enters poverty; relative to individuals who live in a household where the $\mathrm{HoH}$ reports the property is owned outright, individuals who live in a housing association or rental accommodation are significantly less likely to enter poverty. The marginal effects range between 1.8 and 2.4 percentage points. As noted in Section 4.2, this finding is related to the types of benefit income individual's living in these types of accommodation are claiming relative to outright homeowners.

Table 6 highlights that an individual's own subjective assessment of their financial situation is strongly correlated with poverty entry. HoH's who report that their financial situation as 'doing alright', 'just about getting by' or 'finding it quite difficult' are between 1.3 and 5.7 percentage points more likely to enter poverty relative to $\mathrm{HoHs}$ who report their financial situation as 'living comfortably'.

Table 6 also indicates that benefit income and pensions are important for determining poverty entry. Individuals living in a household where the $\mathrm{HoH}$ received income from two or more private or occupational pensions lowered the probability of entering poverty by 1.6 percentage points, relative to individuals who relied on state pension and/or pension credit alone. Finally, similar to the results found for initial poverty, individuals living in a household where the $\mathrm{HoH}$ reported being in receipt of incapacity/severe disability or carers/attendance allowance are significantly less likely to enter poverty, relative to individuals who reported not being in receipt of either of these benefits.

\subsection{Correlations}

One advantage of using a first-order Markov approach is to account for initial conditions and non-random survey attrition. Table 7 summarises the extent of these two issues when modelling low-income dynamics among British pensioners, and also documents a range of tests to determine the sensitivity of the results to the assumptions imposed by the econometric framework.

Table 7 shows strong evidence of unobserved factors which are correlated with initial and conditional poverty status. The correlation coefficient $\rho_{2}$ is negative and statistically significant; implying that pensioners who are initially poor are less likely to remain poor compared to individuals who are initially non-poor (i.e., regression towards the mean). When one considers that this group of individuals has relatively fixed sources of income this suggests that pensioner incomes are not as stable as one might have first assumed.

Table 7 indicates that there was no significant evidence of an unobserved correlation between non-random attrition and poverty status (in either period $t-1$ or $t$ ) among British pensioners.

Rows 2, 3 and 7 of Table 7 imply the sample exhibits an initial conditions problem; whereas the test for exogeneity of non-random attrition could not be rejected. 
Table 7. Model correlations and test statistics

1. Correlations between unobservable components

2. $\rho_{1}$ : Initial poverty and survey retention

3. $\rho_{2}$ : Initial and conditional poverty

4. $\rho_{3}$ : Survey retention and conditional poverty

Test of correlations

7. $\rho_{1}=\rho_{2}=0$ : No evidence of initial conditions $\left(\chi_{2}^{2}\right)$

8. $\rho_{1}=\rho_{3}=0$ : No evidence of non-random attrition $\left(\chi_{2}^{2}\right)$

9. $\rho_{1}=\rho_{2}=\rho_{3}$ : Joint exogeneity $\left(\chi_{3}^{2}\right)$

Test of instruments

12. Inclusion of paternal education in initial poverty equation

13. Inclusion of survey queries in retention equation

14. Exclusion of paternal education in transition equation

15. Exclusion of survey queries in transition equation

16. Exclusion of paternal education \& survey queries in transition equation

Test of normality of residuals

19. Initial poverty equation $\left(\varepsilon_{i, t-1}\right)$

20. Retention equation $\left(\kappa_{i, t}\right)$

21. Transition equation $\left(\vartheta_{i, t}\right)$

$\begin{array}{cl}\text { Estimate } & \mathrm{p}>|z| \\ 0.012 & 0.61 \\ -0.44 & 0.00 \\ -0.03 & 0.91\end{array}$

$14.50 \quad 0.00$

$0.27 \quad 0.87$

$15.45 \quad 0.00$

$\chi_{\text {d.o.f }}^{2} \quad \mathrm{p}>\chi^{2}$

$\begin{array}{ll}7.60 & 0.00\end{array}$

$22.88 \quad 0.00$

$3.83 \quad 0.147$

$4.69 \quad 0.3211$

$8.50 \quad 0.2039$

$\mathrm{p}$ (Skewness) $\mathrm{p}$ (Kurtosis)

$0.00 \quad 0.00$

$0.00 \quad 0.00$

$0.00 \quad 0.00$

However, the test for joint exogoneity is strongly rejected. To summarise, Table 7 indicates that future research using an endogenous switching framework to model pensioner poverty should use a bivariate framework. This is to control for the fact that when modelling poverty transitions between two periods the group of individuals who are initially observed to be in poverty are a non-random sample. More generally, the results suggest that when modelling low-income dynamics among British pensioners, irrespective of the econometric framework, one should account for individual-level unobserved heterogeneity.

\subsubsection{Model identification and sensitivity tests}

The first-order Markov approach has a number of attractive features as discussed in Section 2.2; however, for the estimates to be unbiased requires one to have appropriate instruments. One way to check the suitability of instruments is to rely on functional form for model identification, and include the characteristics used as instruments in equation (3). A statistically significant coefficient would indicate an invalid instrument. Table 7 (row 13) highlights that paternal educational attainment is not statistically significant in the equation for conditional poverty status, after having controlled for it in the equation determining initial poverty status. Now consider the covariates used to control for non-random attrition, Table 7 shows that these play no significant role in the conditional poverty equation. Finally, Table 7 shows that it is possible to exclude covariates which control for both the initial conditions and non-random attrition from the conditional poverty equation (row 16 of Table 7). 
An alternative test for determining whether paternal educational attainment is a plausible instrument to control for the initial conditions problem is to determine whether there exists a correlation between equivalised household permanent income and paternal educational attainment. Separately one also needs to test for a correlation between the variance of equivalised household income (i.e., transitory income) and paternal educational attainment. Permanent income is the sum of real monthly equivalised household expenditure on: accommodation (rent and council tax or mortgage and council tax), food (bought at a supermarket) and energy (oil, gas, electricity and other fuel). The rational behind these tests is as follows: the modelling strategy described in Section 4.3 implies that paternal educational attainment is correlated with permanent income; however, conditional on this is uncorrelated with transitory income. One way to test this assumption is to (separately) regress permanent income and the variance of household income on paternal educational attainment. If paternal education satisfies the conditions for being a suitable instrument, then it should be correlated with permanent income and uncorrelated with transitory income. Appendix B contains the results from two such regressions based on the sample data used in this study; the results indicate there is a strong statistical correlation between permanent income and paternal educational attainment and no statistical correlation between the variance of household income (transitory income) and paternal educational attainment. In order for the latter regression to be valid there should be no evidence of non-random attrition (in order to estimate the variance of equivalised household net income one must observe household income in both survey waves), this is the case for the sample used in this study as shown in Table 7.

One necessary assumption is joint normality of the errors in equations (1)-(3) for tractability purposes; however, it is worth testing whether such an assumption holds for the sample. Table 7 reports that tests based on skewness and kurtosis, these tests reject the null hypothesis that the sample moments satisfy the normality assumption. An alternative test is to graphically determine the extent of non-normality. Appendix $\mathrm{C}$ contains quantile plots of the residuals from 1-3 versus the quantiles of a Gaussian distribution; these plots also indicate that the joint normality assumption is unlikely to hold. It is important to note these shortcomings when interpreting the results; however as Cappellari and Jenkins (2004) show in their study it is also worth noting that the model is able to accurately predict transition probabilities of sample respondents, for example the model predicts the average probability of poverty entry (persistence) among respondents present at $t-1$ and $t$ is $0.0958(0.6848)$ the corresponding figure based on raw sample transitions is $0.0949(0.6844)$.

In order to determine the sensitivity of the results reported in Section 5; two alternative versions of the model were estimated. In these respective specifications, an individual is defined as being in poverty if their equivalised net real household income is below $50 \%$ and $70 \%$ of the population median income. In both cases there is a correlation between initial and conditional poverty; namely mean reversion. Similar to Cappellari and Jenkins (2004) the estimates imply estimated poverty persistence and entry rates rise, the higher the poverty threshold. To summarise, the vast majority of robustness tests suggest that the assumptions underlying the model are satisfied. 


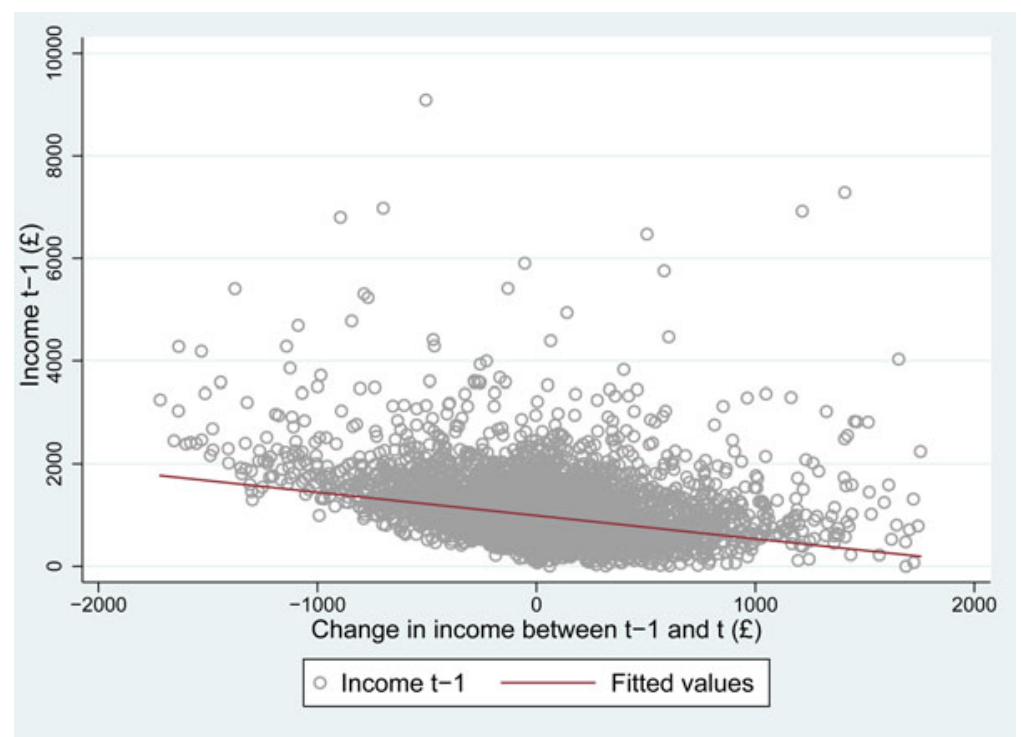

Figure 3. (colour online) Level of income in $t-1$ versus change in income between $t-1$ and $t$.

Notes: Income refers to monthly household net equivalised income which has been adjusted to account for inflation (2005 prices).

\section{Model implications}

\subsection{Changes in income}

The model correlations show that $\rho_{2}$ is negative and statistically significant, which implies there is a strong negative correlation between unobserved factors determining initial poverty and conditional poverty status, put another way there is regression towards the mean. ${ }^{44}$ Graphically, this is equivalent to a negative correlation between the level of income at $t-1$ and the change in income between $t-1$ and $t .^{45}$ Figure 3 shows this relationship based on the sample data used in this study.

Figure 3 is consistent with the sign of $\rho_{2}$ reported in Table 7 ; highlighting that income in retirement is not as stable as one might have initially assumed and also demonstrating the drawback of using a simple dichotomous measure such as 'poverty status' to group together clearly different households.

Whilst Figure 3 graphically assessed the change in equivalised income between $t-1$ and $t$ and the income level at $t-1$ it does this across all households, in Figures 4 and 5 I show the extent of the changes in net equivalised income using boxplots, depicting the change in income between $t-1$ and $t$ conditional on poverty status at $t-1$.

\footnotetext{
44 In Section 5.1 I analyse changes in income with respect to the balanced panel; survey attrition implies that we do not observe household income at period $t$ for all households. However, the results in Section 4 indicate that there is no evidence of non-random attrition for the sample used in this study and therefore analysing the sample in this way is feasible.

45 This was first shown in the context of UK wage dynamics by Stewart and Swaffield (1999).
} 


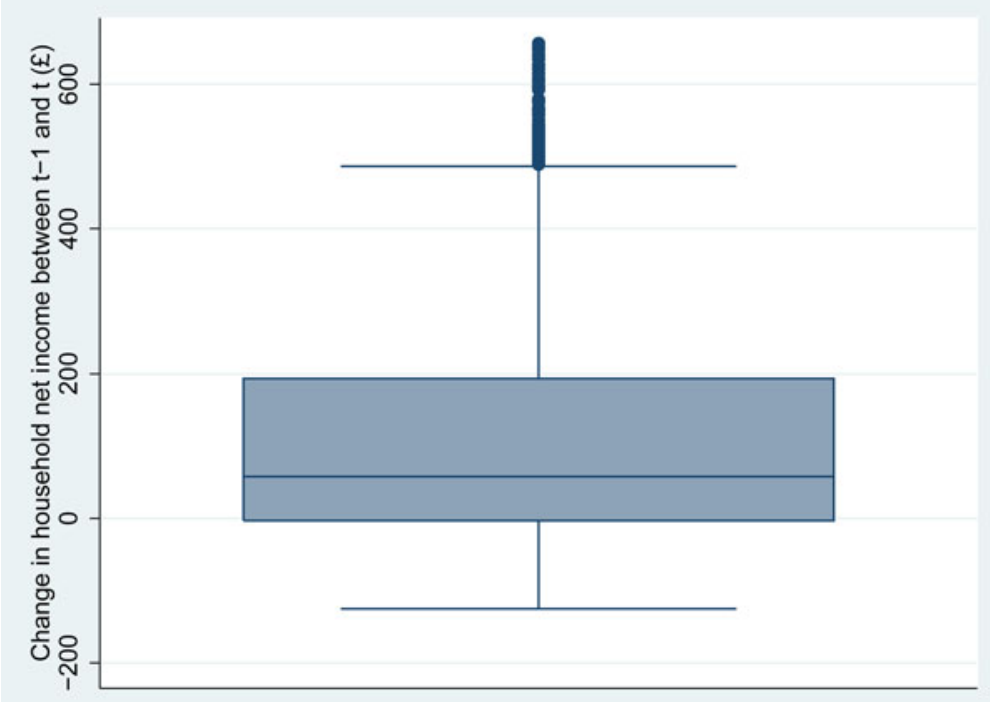

Figure 4. (colour online) Boxplot of change in income between 2010/11 and 2011/12 among initially poor individuals.

Notes: Income refers to monthly household net equivalised income which has been adjusted to account for inflation (2005 prices).

The median (mean) change in monthly net household income among initially poor households between $t-1$ and $t$ is $£ 48.20$ ( $£ 210.89$ ). On the other hand, the same statistic for non-poor households is $-£ 4.47(-£ 87.38$ ). These statistics and Figures 4 and 5 show that there are significant variations in household income changes between $t-$ 1 and $t$ particularly among non-poor households at $t-1$.

Whilst Figures 3-5 serve as a useful benchmark to analyse equivalised householdlevel changes in income between $t-1$ and $t$, what is arguably more interesting, given that the aim is to understand income dynamics is to determine which subcomponents of individual income are driving such changes. Understanding Society contains information on the components of individual's income, which in turn (either solely or jointly) make up household income. In order to understand the results driving the dynamics implied by the model and Figures 3-5, Table 8 describes the mean changes in income components (restricted to individuals who reported being in receipt of a particular income source at $t-1$ ) between $t-1$ and $t$ and by initial poverty status.

Table 8 shows that conditional on initial poverty status there are clear differences in the average change in the subcomponents of individual income. This is consistent with the correlation estimate of $\rho_{2}$ reported in Table 7 and Figures 3-5. Table 8 also shows that certain components of an individual's income change more than others and hence will have a more profound effect on household income; for example investment, pension and social benefit income are particularly important in increasing individual (and thus household) income among initially poor individuals; whereas it declines for individuals who are initially non-poor. ${ }^{46}$ Table 8 also shows the particularly strong impact social benefit income (in particular carer's allowance, disability living allowance and 


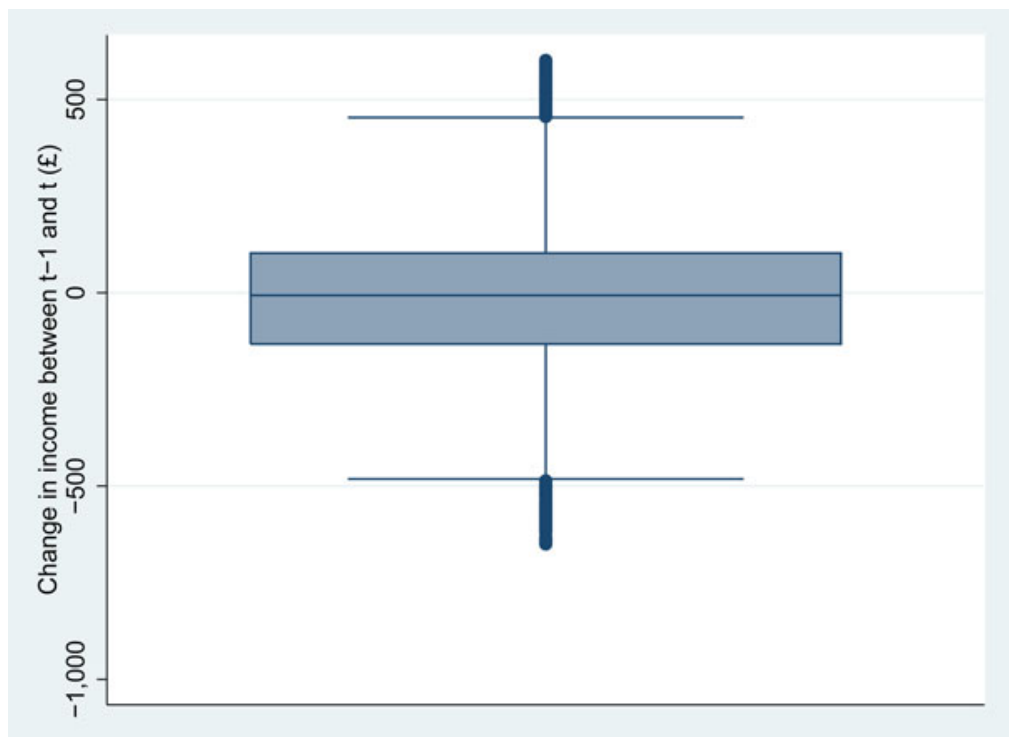

Figure 5. (colour online) Boxplot of change in income between 2010/11 and 2011/12 among initially non-poor individuals.

Notes: Income refers to monthly household net equivalised income which has been adjusted to account for inflation (2005 prices).

incapacity benefit income) has on determining an individual's poverty status; the magnitude of the changes observed in social benefit income is similar to that observed for pension income between $t-1$ and $t$. An alternative way to highlight the importance of social benefit income in determining an individual's income position is to consider the average change in income (by initial poverty status) among individuals who at $t-$ 1 reported not being in receipt of social benefit income, but by $t$ did report being in receipt of some form of social benefit income: the average change in social benefit income was $£ 440.43$ among individuals who exited poverty between $t-1$ and $t$, moreover no individuals in the sample entered poverty between $t-1$ and $t$ and also reported an increase (from zero) in their social benefit income.

Table 8 also highlights the importance of labour income; however this is only relevant to a very small proportion of the sample. Cappellari and Jenkins (2004) find evidence of a regression towards the mean based on BHPS data of working age households; however for working age individuals significant changes in their individual (and hence household) income is possible through the labour market for example gaining employment. In the case of retired individuals a transition back into paid employment in known as 'unretirement' and whilst it prevalence varies significantly between countries, unretirement studies have consistently shown a return to work provides a non-trivial source of income in retirement (Maestas, 2010; Kanabar, 2015). In this study, very few individuals $(<1 \%$ sample) transition from retirement

46 Investment and pension income are made up of various income streams including private pension income, rental income, annuity income and individual's/spouse's employer pension income. 
Table 8. Changes in components of income between $t-1$ and $t$

\begin{tabular}{|c|c|c|c|c|}
\hline Component of income & Poor $_{t-1}(£)$ & $\sigma_{\text {poor }}$ & Non-poor $_{t-1}(\mathfrak{f})$ & $\sigma_{\text {non-poor }}$ \\
\hline All labour income & -29.74 & 131.47 & -87.90 & 150.09 \\
\hline Miscellaneous & -27.29 & 136.0 & -106.89 & $2,291.1$ \\
\hline Private benefit & -59.39 & 93.31 & -52.60 & 110.02 \\
\hline Investment & 29.13 & 383.3 & -18.42 & $2,016.26$ \\
\hline Pension & 64.66 & 620.71 & -163.55 & $4,485.03$ \\
\hline Social benefits & 59.87 & 180.92 & -13.09 & 367.11 \\
\hline
\end{tabular}

Notes: Income components are at the individual level and quoted in January 2010 prices. Sample restricted to individuals who report being receipt of income component at $t-1$.

back into paid employment or self-employment; however among individuals who do unretire and were initially poor, the average change in household income between $t-1$ and $t$ is $£ 768$ (2005 prices) and $80 \%$ of these individuals exit poverty.

\subsection{Stylised examples}

Table 9 assesses the importance of individual and household-level characteristics on poverty entry, persistence and duration by comparing individuals from different types of pensioner households. ${ }^{47}$

The reference male pensioner (case 1) is aged 74 (the median age of HoHs at $t-1$ ), lives in a household whose $\mathrm{HoH}$ is in good health, owns their home outright, is educated to GCSE level, is single (never married), has income from one occupational or employer pension, has no other sources of income, does not receive any disability benefits and reports their financial situation as 'quite difficult'. The predicted probability of this male persisting in poverty is 0.53 and the probability he enters poverty is 0.137 . For this man the unconditional probability of him entering poverty is 0.227 and the mean and median duration of his poverty spell length is 2.13 and 1.09 years, respectively, whilst the mean and median duration between poverty spells is 7.24 and 4.67 years. As Cappellari and Jenkins (2004) note the fact that median spell lengths are smaller than mean spell lengths is due to the fact that spell-lengths are skewed; typically one would expect many short spells and fewer longer spells. Nonetheless, the results indicate that there is significant individual heterogeneity even for individuals with identical characteristics underlined by the differences between the mean and median spell-lengths (Cappellari and Jenkins, 2004, 12).

Case 2 is identical to case 1 except the male pensioner reports having a limiting illness and is in receipt of incapacity/severe disability benefit. For this individual the predicted persistence and entry rate into poverty is lower: 0.33 and 0.09 , respectively. The spell-length before this male pensioner relapses back into poverty is longer than in case 1 . The unconditional probability of being poor is slightly lower at 0.12 . This is

47 These estimates are generated using the point estimates in Tables 3-5 and expressions in appendix A. This requires the additional assumption that persistence and entry rates as having reached their steady-state values. 
Table 9. Predicted state probabilities and durations for stylised individuals

\begin{tabular}{|c|c|c|c|c|c|c|}
\hline Characteristics & $\begin{array}{l}\text { Poverty } \\
\text { persistence } \\
\text { rate }\end{array}$ & $\begin{array}{l}\text { Poverty } \\
\text { entry rate }\end{array}$ & $\begin{array}{l}\text { Poverty } \\
\text { exit rate }\end{array}$ & $\begin{array}{l}\text { Probability } \\
\text { being poor }\end{array}$ & $\begin{array}{l}\text { Poverty spell } \\
\text { (mean, median) }\end{array}$ & $\begin{array}{l}\text { Non-poverty } \\
\text { spell (mean, } \\
\text { median) }\end{array}$ \\
\hline $\begin{array}{l}\text { Case 1: Aged 74, HoH is in good health, owns their } \\
\text { home outright, educated to GCSE level, is single } \\
\text { (never married), income from one occupational } \\
\text { or employer pension, no other sources of income, } \\
\text { does not receive any disability benefits and } \\
\text { reports their financial situation as 'quite difficult' }\end{array}$ & 0.53 & 0.13 & 0.46 & 0.22 & $(2.12,1.09)$ & $(7.24,4.66)$ \\
\hline $\begin{array}{l}\text { Case 2: Case } 1 \text { except the man reports having a } \\
\text { limiting illness and is in receipt of incapacity/ } \\
\text { severe disability benefit }\end{array}$ & 0.33 & 0.09 & 0.66 & 0.12 & $(1.50,0.63)$ & $(11,7.27)$ \\
\hline $\begin{array}{l}\text { Case } 3 \text { : Case } 2 \text { except the man has no occupational } \\
\text { pension and relies on state pension (and pension } \\
\text { credit) income alone }\end{array}$ & 0.42 & 0.10 & 0.57 & 0.15 & $(1.74, .814)$ & $(9.76,6.41)$ \\
\hline $\begin{array}{l}\text { Case 4: Case } 1 \text { except the man finds has a limiting } \\
\text { illness but does not receive any kind of disability } \\
\text { benefit income }\end{array}$ & 0.81 & 0.06 & 0.18 & 0.24 & $(5.28,3.30)$ & $(15.96,10.71)$ \\
\hline $\begin{array}{l}\text { Case 5: female, widowed, aged 74, HoH reports } \\
\text { being in good health, HOH has a limiting illness/ } \\
\text { disability, does not receive any disability benefits, } \\
\text { has one occupational/employer pension, owns } \\
\text { their home outright, is educated to GCSE } \\
\text { standard and reports their financial situation as } \\
\text { 'very difficult' }\end{array}$ & 0.59 & 0.04 & 0.40 & 0.10 & $(2.45,1.32)$ & $(21.41,14.49)$ \\
\hline $\begin{array}{l}\text { Case 6: Case } 5 \text { except the female reports being in } \\
\text { receipt of investment income }\end{array}$ & 0.66 & 0.04 & 0.33 & 0.11 & $(2.96,1.68)$ & $(22.62,15.33)$ \\
\hline
\end{tabular}

Notes: Estimates are based on expressions 7, 8, point estimates from Tables 3-5 and Appendix A. Poverty and non-poverty spells are quoted in years. 
consistent with the estimation results, which found that particular forms of benefit income actually reduce the likelihood of being in poverty but does not reflect an increase in an individual's actual standard of living.

Case 3 is identical to case 2 except the male pensioner has no occupational pension and relies on state pension (and pension credit) alone. The effect of these two factors raises the probability of poverty entry and probability persistence to 0.42 and 0.10 , respectively. Similarly the unconditional poverty rate is higher $(0.15)$ than in case 2. The mean and median spell-length of poverty is also larger than in case 2 at 1.75 and 0.819 years, respectively. Intuitively, the spell-length between each poverty period is lower ( 9.84 and 6.47 years at the mean and median, respectively).

Case 4 is identical to case 1 except the male pensioner has a limiting illness but does not receive any kind of disability benefit income. Relative to case 1 this leads to a significant increase in the persistence and the unconditional probability of entering poverty ( 0.81 and 0.24 , respectively); it also increases the mean and median period spent in poverty $(5.28,3.30$ years) relative to case 1 .

Cases 5 and 6 consider the situation when the individual is a female pensioner. The reference female pensioner is a widow, aged 74, lives in a household where the $\mathrm{HoH}$ reports being in good health although does have a limiting illness/disability, does not receive any disability benefits, has one occupational/employer pension, owns their home outright, is educated to GCSE level and reports her financial situation as 'very difficult'. This predicted probability of this female pensioner entering poverty is 0.04 , whilst the predicted persistence rate is 0.59 . The unconditional poverty rate is 0.10 and the median (mean) poverty spell-length is $2.45(1.32)$ years, whilst the median (mean) period between poverty spells is $14.63(21.61)$ years.

Case 6 is identical to case 5 except the female reports being in receipt of investment income. The poverty entry rate for this female is 0.04 and the probability of persisting in poverty is 0.66 . In case 6 , the length of time between periods of poverty is slightly larger than in case 5, the median (mean) duration between is 15.33 (22.62) years; however the mean and median poverty spell-length is itself slightly longer (2.96, 1.68 years).

Cases 1-6 highlight the importance of particular individual and household-level characteristics such as the presence of disability benefits, an occupational pension, investment income, housing tenure and contemporaneous subjective financial position in determining the probability that a pensioner will enter, persist or relapse into poverty. Table 9 also highlights that duration estimates based on a first-order Markov framework (assuming steady-state values) are highly sensitive to changes in the poverty persistence and entry rate. The results also support the findings in Bardasi et al. (2002) and the DWP low-income dynamics publication that pensioners on low incomes or with characteristics associated with being in a low-income household have a relatively high poverty persistence rate. A recent report by the DWP which investigated non-take up of Pension Credit found a major factor cited by individuals was that they felt 'bad for asking for help from the government' (Radford et al., 2012, 18). Therefore resources should be focused on trying to change such attitudes; for example through consultation groups and targeted information campaigns.

Finally, Table 9 also indicates that there is heterogeneity in both predicted poverty persistence and poverty entry rates. These findings suggest that predicted state 
probabilities of being poor are related to both periods spent out of poverty and also in poverty. ${ }^{48}$ This necessitates the need for anti-poverty policies which reduce the extent to which individual relapse back into poverty and also programmes such as Pension Credit which increase individual incomes which fall below a particular 'low-income' threshold. Active labour market policies are often cited as being an effective in combating poverty (Martin, 1998); however, such programmes are often aimed at working age individuals in the UK, in the case of pensioners this unlikely to be a feasible and effective solution partly also due to cultural factors associated with retirement in the UK (Kohli, 1991). Therefore policies should be aimed at trying to reduce contemporary pensioner poverty through alternative measures, perhaps by some kind of hybrid intervention which would be more akin to a paidlin kind benefit associated with voluntary or paid work in order reduce the stigma or social perception associated with returning to work post retirement.

\section{Conclusion}

Similar to many advanced economies the UK population has a significant proportion of older people: as of 2014 it was estimated that 11.4 million individuals or $17.7 \%$ of the population are aged 65 and over (ONS, 2015). Therefore it is important to understand the income changes experienced by the poorest members of this group of individuals and the implications this has for policy. This study has provided the first estimates of poverty dynamics of pensioner households which are robust to selection biases which arise due to initial conditions and non-random sample attrition.

The econometric framework followed in this paper has shown that there exist unobserved factors, which determine initial and conditional poverty status. The sign of this correlation is negative indicating regression towards the mean. From a methodological perspective this implies evidence of an initial conditions problem, studies which analyse income dynamics among pensioner households and ignore this issue will get bias results. It also highlights that contrary to what one might assume pensioner incomes do exhibit a degree of volatility and are not completely stable, this is noteworthy given the limited number of income sources available to this group of individuals. Finally the results indicate no evidence of a correlation between low income and non-random attrition.

Pensioners exhibit a high degree of poverty persistence; therefore it is important to understand which components of income are driving the finding of mean reversion. The results indicate that social benefit, investment and pension income increased between $t-1$ and $t$ for initially poor individuals, whilst the opposite is true for the nonpoor and moreover the variance of changes in these income components is large. This underlines the extent of individual-level heterogeneity among initially "poor pensioners' and the importance for controlling for unobserved characteristics. This is also supported by the finding that there is a large degree of variation in poverty persistence rates even for individuals with the same characteristics. It suggests that there

48 Additional analyses of stylised cases were estimated for better-off individuals; in these cases there was variation in both poverty entry and persistence rates albeit the predicted entry rates are very low. 
is a degree of variation in household income at older ages, which is interesting given few pensioners return to the labour market post retirement, however it is important to note that the labour market is likely to be an important factor in explaining the heterogeneity in retirement income predominantly through lifetime labour supply, earnings and pension contributions.

One finding which is particularly important is the association between an individual's standard of living and the benefit income they are in receipt of. The analysis shows that disability/incapacity benefit income and carers or attendance allowance play an important role in determining both initial and conditional poverty status. However being in receipt of such benefits does not to imply an individual is somehow 'better off', or alternatively correspond to a higher standard of living. This highlights that other measures of deprivation other than those based solely on income such as material deprivation are important in order to determine pensioner living standards.

The findings indicate specific factors play a role in determining initial and conditional poverty status: educational attainment ( $\mathrm{HoH}$ and paternal), social benefit income, housing tenure, health, caring, having a limiting illness and the presence of an occupational or private pension. Policies which emphasise the role of retraining in order to reduce re-entry into poverty or unemployment such as Employment Support Allowance tend to be directed at working-age cohorts, partly due to the fact that retirement in the UK is largely seen as permanent withdrawal from the labour market (Banks and Smith, 2006). Current policies aimed at existing pensioners who are living in poverty only boost retirement income, but do not actually tackle the root causes which have led an individual to be poverty in the first place. Indeed, as retirement income is to a large extent a function of lifetime labour supply and earnings (and hence deferred income) any potential policy which attempted to do so would need to be carefully devised and cost effective. Moreover, previous research has highlighted the strong disincentives Pension Credit can generate (in terms of high marginal tax rates) should a poor pensioner wish to return to work (Clark, 2001; Brewer and Emmerson, 2003). A report based on representative British data estimated 1.2 million pensioners in 2008/2009 had no income sources other than state pension and benefit income (Palmer, 2010). Therefore, whilst policymakers have introduced a raft of policies including auto enrolment and increasing the age at which individuals are eligible to claim their state pension, these target current working age individuals in order to reduce pensioner poverty among future pensioner cohorts and does not resolve the issue of reducing contemporaneous pensioner poverty. The results from this study highlight some of the methodological factors which should be accounted for when trying to improve our understanding of pensioner income dynamics.

\section{Acknowledgements}

The author would like to thank Steve Pudney, Sonia Bhalotra and Ben Etheridge who provided constructive feedback on early drafts of the paper. The author would also like to thank session participants at the Understanding Society 2015 Conference (Essex, UK) and IARIW 2016 conference (Dresden, Germany). 


\section{References}

Aassve, A., Burgess, S. M., Dickson, M., and Propper, C. (2006) Modelling poverty by not modelling poverty: an application of a simultaneous hazards approach to the UK. LSE STICERD Research Paper No. CASE106.

Arranz, J. and Canto, O. (2008) Measuring the effect of spell recurrence on poverty dynamics: Evidence from Spain. p. 17.

Arulampalam, W. and Stewart, M. B. (2009) Simplified implementation of the Heckman estimator of the dynamic Probit model and a comparison with alternative estimators. Oxford Bulletin of Economics and Statistics, 71(5): 659-681.

Ayllón, S. (2015) Youth poverty, employment, and leaving the parental home in Europe. Review of Income and Wealth, 61(4): 651-676.

Banks, J. and Institute for Fiscal Studies, eds. (2006) Retirement, Health and Relationships of the Older Population in England: The 2004 English Longitudinal Study of Ageing (Wave 2). London: Institute for Fiscal Studies.

Banks, J. and Smith, S. (2006) Retirement in the UK. Oxford Review of Economic Policy, 22(1): 40-56.

Bardasi, E., Jenkins, S., and Rigg, R. (2002) Retirement and the income of older people: a British perspective. Ageing and Society, 22(2): 131-159.

Behrman, J. and Taubman, P. (1990) The intergenerational correlation between children's adult earnings and their parent's income: results from the Michigan Panel Survey of Income Dynamics. Review of Income and Wealth, 36(2): 115-127.

Bethlehem, J., Cobben, F., and Schouten, B. (2011) Handbook of Nonresponse in Household Surveys. Hoboken, NJ: John Wiley \& Sons.

Bhuller, M., Brinch, C., and Konigs, S. (2016) Time aggregation and state dependence in welfare receipt. Forthcoming, Economic Journal.

Biewen, M. (2009) Measuring state dependence in individual poverty histories when there is feedback to employment status and household composition. Journal of Applied Econometrics, 24(7): 1095-1116.

Blundell, R. and Etheridge, B. (2010) Consumption, income and earnings inequality in Britain. Review of Economic Dynamics, 13(1): 76-102.

Blundell, R., Meghir, C., and Smith, S. (2002) Pension incentives and the pattern of early retirement. The Economic Journal, 112(478): C153-C170.

Boskin, M. and Nold, F. (1975) A Markov model of turnover in aid to families with dependent children. Journal of Human Resources, 10(4): 467.

Bozio, A., Emmerson, C. and Tetlow, G. (2011) How much do lifetime earnings explain retirement resources? Institute for Fiscal Studies Working Paper, 11(02).

Brewer, M. and Emmerson, C. (2003) Two Cheers for the Pension Credit? IFS Briefing note no. 39. London: Institute for Fiscal Studies.

Brewer, M., Browne, J., Emmerson, C., Goodman, A., Muriel, A., and Tetlow, G. (2007) Pensioner poverty over the next decade: what role for tax and benefit reform? Technical report.

Buddelmeyer, H. and Verick, S. (2008) Understanding the drivers of poverty dynamics in Australian households*. Economic Record, 84(266): 310-321.

Burgess, S. and Propper, C. (1998) An economic model of household income dynamics, with an application to poverty dynamics among American women. CASEpaper, CASE/9. Centre for Analysis of Social Exclusion, London School of Economics and Political Science, London, UK.

Campbell, J. and Cocco, J. (2007) How do house prices affect consumption? Evidence from micro data. Journal of Monetary Economics, 54(3): 591-621.

Cappellari, L. and Jenkins, S. (2003) Multivariate probit regression using simulated maximum likelihood. Stata Journal, 3(3): 278-294. 
Cappellari, L. and Jenkins, S. (2004) Modelling low income transitions. Journal of Applied Econometrics, 19(5): 593-610.

Cappellari, L. and Jenkins, S. (2006) Calculation of multivariate normal probabilities by simulation, with applications to maximum simulated likelihood estimation. The Stata Journal, 6(2): $156-189$.

Cappellari, L. and Jenkins, S. (2008) Estimating low pay transition probabilities accounting for endogenous selection mechanisms. Journal of the Royal Statistical Society: Series C (Applied Statistics), 57(2): 165-186.

Clark, T. (2001) Recent Pensions Policy and the Pension Credit. London: Institute for Fiscal Studies.

Crawford, R. and O'Dea, C. (2014) Retirement sorted? The adequacy and optimality of wealth among the near-retired.

Cuervo, Y. D. and Pudney, S. (2013) Measuring poverty persistence with missing data with an application to Peruvian panel data. ISER Working Paper No. 2013-22. Essex, UK.

Devicienti, F. (2002) Poverty persistence in Britain: a multivariate analysis using the BHPS 1991 1997. Journal of Economics, 77(1): 307-340.

Diamond, P. A. and Hausman, J. A. (1984) Individual retirement and savings behavior. Journal of Public Economics, 23(1-2): 81-114.

Disney, R., Henley, A., and Stears, G. (2002) Housing costs, house price shocks and savings behaviour among older households in Britain. Regional Science and Urban Economics, 32 (5): 607-625.

Deaton, A. (1999) Inequalities in income and inequalities in health (No. w7141). National bureau of economic research.

DWP. (2015) Benefit expenditure and caseload tables 2015.

DWP. (2014) Households below Average Income: An analysis of the income distribution 1994/ 95-2012/13.

Fisher, F. (2015) Income reporting in the initial waves of panel surveys: Evidence from the Understanding Society. ISER Scientific Conference presentation.

Fusco, A. and Islam, N. (2012) Understanding the drivers of low income transitions in Luxembourg. Research on Economic Inequality, 20: 367-391.

Gourieroux, C. and Monfort, A. (1997) Simulation-Based Econometric Methods. Oxford: Oxford University Press.

Grawe, N. (2006) Lifecycle bias in estimates of intergenerational earnings persistence. Labour Economics, 13(5): 551-570.

Hancock, R., Morciano, M., and Pudney, P. (2015) Disability costs and equivalence scales in the older population in Great Britain. Review of Income and Wealth, 61(3): 494-514.

Heckman, J. (1981) Statistical models for discrete panel data. In Charles F. Manski and Daniel L. McFadden, eds. Structural Analysis of Discrete Data with Econometric Applications. Cambridge: MIT Press, pp. 114-178.

Jarvis, S. and Jenkins, S. (1997) Low income dynamics in 1990s Britain. Fiscal Studies, 18(2): $123-142$.

Jenkins, S. (2011) Changing Fortunes: Income Mobility and Poverty Dynamics in Britain. Oxford: Oxford University Press.

Jenkins, S. and Cappellari, L. (2008) The Dynamics of Social Assistance Receipt. OECD Social, Employment and Migration Working Papers 67.

Jenkins, S. and Rigg, R. (2001) The dynamics of poverty in Britain: Department for Work and Pensions Research Report 157.

Jenkins, S., Rigg, J., and Devicienti, F. (2001) The Dynamics of Poverty in Britain. Leeds: Corporate Document Services for the Department for Work and Pensions.

Jenkins, S., Cappellari, L., Lynn, P., Jackle, A., and Sala, E. (2006) Patterns of consent: evidence from a general household survey. Journal of the Royal Statistical Society: Series A (Statistics in Society), 169(4): 701-722. 
Jones, A., Koolman, X., and Rice, N. (2006) Health-related non-response in the British Household Panel Survey and European Community Household Panel: using inverse-probability-weighted estimators in non-linear models. Journal of the Royal Statistical Society: Series A (Statistics in Society), 169(3): 543-569.

Jones, A., Rice, N., and Roberts, J. (2010) Sick of work or too sick to work? Evidence on selfreported health shocks and early retirement from the BHPS. Economic Modelling, 27(4): 866-880.

Kanabar, R. (2015) Post-retirement labour supply in England. The Journal of the Economics of Ageing, 6: 123-132.

Kapteyn, A., Alessie, R., and Lusardi, A. (2005) Explaining the wealth holdings of different cohorts: productivity growth and Social Security. European Economic Review, 49(5): 13611391.

Knies, G. (2014) Understanding Society User Guide: Waves 1-5. Institute for Social and Economic Research, University of Essex.

Kohli, M. (1991) Time for Retirement: Comparative Studies of Early Exit from the Labor Force. Cambridge: Cambridge University Press.

Lancaster, T. (1990) The Econometric Analysis of Transition Data. Cambridge: Cambridge University Press.

Little, R. J. and Rubin, D. B. (2014) Statistical Analysis with Missing Data. Hoboken, NJ: John Wiley \& Sons.

Lowe, S. G., Searle, B. A. and Smith, S. J. (2012) From housing wealth to mortgage debt: the emergence of Britain's asset-shaped welfare state. Social Policy and Society, 11(1): 105-116.

Lusardi, A. and Mitchell, O. (2007) Baby Boomer retirement security: the roles of planning, financial literacy, and housing wealth. Journal of Monetary Economics, 54(1): 205-224.

Maestas, N. (2010) Back to work expectations and realizations of work after retirement. Journal of Human Resources, 45(3): 718-748.

Martin, J. (1998) What Works Among Active Labour Market Policies. OECD Labour Market and Social Policy Occasional Papers 35.

Nicoletti, C. and Ermisch, F. (2008) Intergenerational earnings mobility: changes across cohorts in Britain. BE Journal of Economic Analysis \& Policy, 7(2).

OECD (2011) Pensions at a Glance 2011: Retirement-income Systems in OECD and G20 Countries. Paris, France: OECD Publishing.

ONS (2014) Life Expectancy at Birth and at Age 65 by Local Areas in England and Wales 2011 2013.

ONS (2015) Annual Mid-year Population Estimates 2014. Population Estimates Unit.

Palmer, G. (2010) Older people with no private income. http://www.poverty.org.uk/65/index. shtml

Radford, L., Taylor, L., and Wilkie, C. (2012) Pension credit eligible non-recipients barriers to claiming. Research Report, No. 819, Department for Work and Pensions.

Shin, D. and Solon, D. (2011) Trends in men's earnings volatility: What does the Panel Study of Income Dynamics show? Journal of public Economics, 95(7): 973-982.

Stevens, A. H. (2011) Poverty Transitions. United States of America: Center for Poverty Studies, University of California, Davis.

Stewart, M. and Swaffield, J. (1999) Low pay dynamics and transition probabilities. Economica, 66(261): 23-42.

Stewart, M. (2003) The relationship between the financial position of pensioners and their working-life earnings levels. In Royal Economic Society Conference, University of Warwick. Citeseer.

Stewart, M. B. (2009) The estimation of pensioner equivalence scales using subjective data. Review of Income and Wealth, 55(4): 907-929.

Stronks, K., van de Mheen, H., Van Den Bos, J., and Mackenbach, J. P. (1997) The interrelationship between income, health and employment status. International Journal of Epidemiology, 26(3): 592-600. 
Train, K. (2009) Discrete Choice Models with Simulation. Cambridge, UK: Cambridge University Press.

Watson, D. (2002) Sample attrition between waves 1 and 5 in the European Community Household panel. European Sociological Review, 19(4): 361-378.

Wooldridge, J. (2005) Simple solutions to the initial conditions problem in dynamic, nonlinear panel data models with unobserved heterogeneity. Journal of Applied Econometrics, 20(1): $39-54$.

\section{Appendix}

\section{Appendix A: Poverty durations}

Cappellari and Jenkins (2004) show in the case of the model structure imposed by (1) (3) and assuming a stationary environment that the durations of interest are defined as:

\begin{tabular}{ll}
\hline \hline Duration & \multicolumn{1}{c}{ Statistics } \\
\hline Mean poverty & $1 /\left(1-m_{i}\right)$ \\
Median poverty & $\log (0.5) / \log \left(m_{i}\right)$ \\
Mean non-poverty & $1 / l_{i}$ \\
Median non-poverty & $\log (0.5) / \log \left(1-l_{i}\right)$ \\
Unconditional poverty & $e_{i} /\left(e_{i}+1-s_{i}\right)$ \\
\hline \hline
\end{tabular}

Notes: Where $m_{i}, l_{i}$ and $e_{i}$ refer to corresponding steady-state values of $m_{i, t}, l_{i, t}$ and $e_{i, t}$, respectively.

\section{Appendix B: Testing instrument validity}

Permanent income and paternal educational attainment.

A statistically significant coefficient estimate implies paternal educational attainment is a suitable instrument.

Table B1. Estimation results: instrument validity I

\begin{tabular}{ll}
\hline \hline Variable & Coefficients are different (S.E.) \\
\hline Father has a post-school qualification or degree & $88.655^{* * *}(17.336)$ \\
Intercept & $872.178^{* * *}(5.573)$ \\
$N$ & 12,904 \\
$R^{2}$ & 0.005 \\
$F_{(1,5683)}$ & 26.153 \\
\hline
\end{tabular}

Variance of income and paternal educational attainment.

A statistically insignificant coefficient estimate implies paternal educational attainment is a suitable instrument. 
Table B2. Estimation results: instrument validity II

\begin{tabular}{ll}
\hline \hline Variable & \multicolumn{1}{c}{ Coefficient (S.E.) } \\
\hline Father has a post-school qualification or degree & $2278.777(1608.105)$ \\
Intercept & $959.515^{* * *(305.101)}$ \\
$N$ & 11,108 \\
$R^{2}$ & 0.001 \\
$F_{(1,4935)}$ & 2.008 \\
\hline
\end{tabular}

Appendix C: Quantile plots of equation residuals versus a Gaussian distributed random variable
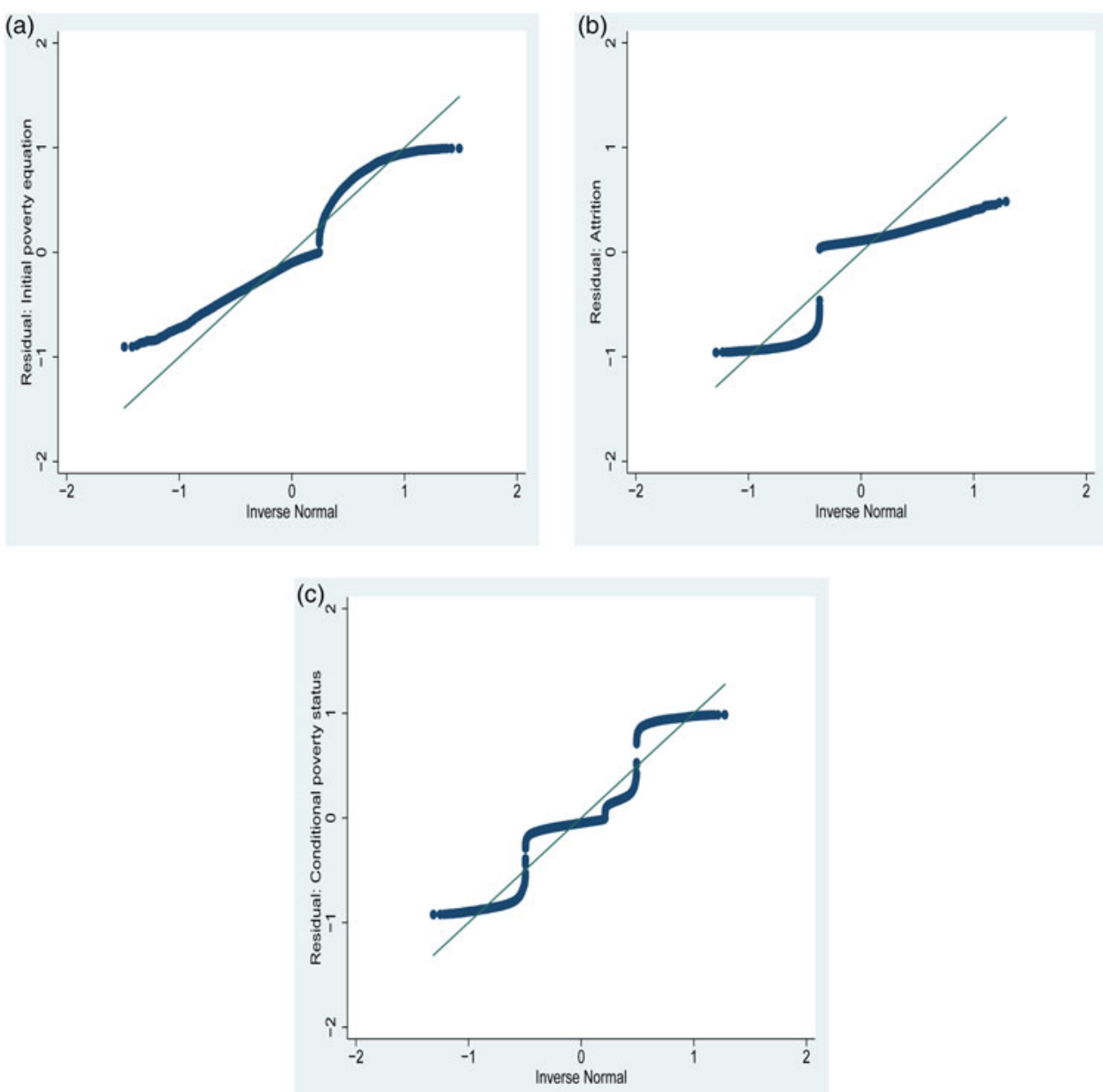

Appendix C. (colour online) (a) Initial poverty equation. (b) Retention equation. (c) Transition equation. 